\title{
USP/IFSC/SBI
}

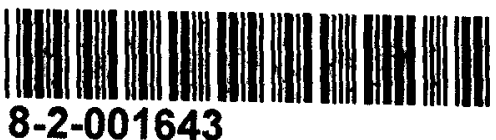

\section{Estudo da formação de filmes de poli(o-etoxianilina) visando a sua aplicação em língua eletrônica}

\author{
Humberto Hissashi Takeda
}

Dissertação apresentada à Área Interunidades em Ciência e Engenharia de Materiais, da Universidade de São Paulo, para obtenção do título de Mestre em Ciências e Engenharia de Materiais.

Orientador: Prof. Dr. Luiz Henrique Capparelli Mattoso 
Takeda, Humberto Hissashi

"Estudo da formação de filmes de poli(o-etoxianilina) visando a sua aplicação em língua eletrônica" Humberto Hissashi Takeda - São Carlos, 2004

Dissertação (Mestrado) - Interunidades Ciência e Engenharia de Materiais da Universidade de São Paulo, 2004 - páginas: 76

Área: Ciência e Engenharia de Materiais

Orientador: Prof. Dr. Luiz Henrique Capparelli Mattoso

1. POEA, língua eletrônica, sensor.

1. Título 
MEMBROS DA COMISSÃO JULGADORA DA DISSERTAÇÃO DE MESTRADO DE HUMBERTO HISSASHI TAKEDA, APRESENTADA Ȧ ÁREA INTERUNIDADES CIÊNCIA E ENGENHARIA DE MATERIAIS, UNIVERSIDADE DE SÃO PAULO, EM 16/12/2004.

COMISSÃO JULGADORA:

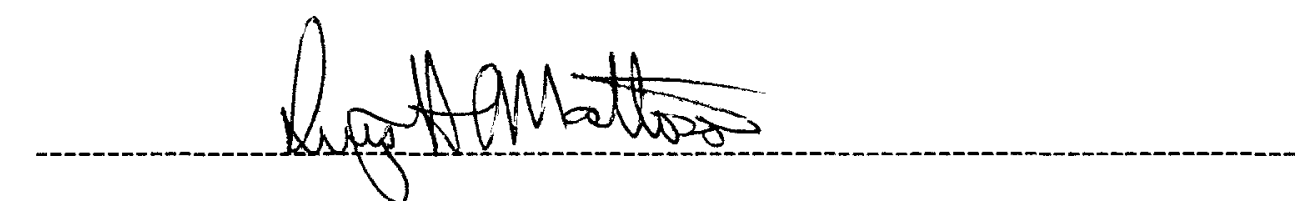

Prof. Dr. Luiz Henrique Capparelli Mattoso ( Orientador e Presidente) - EMBRAPA
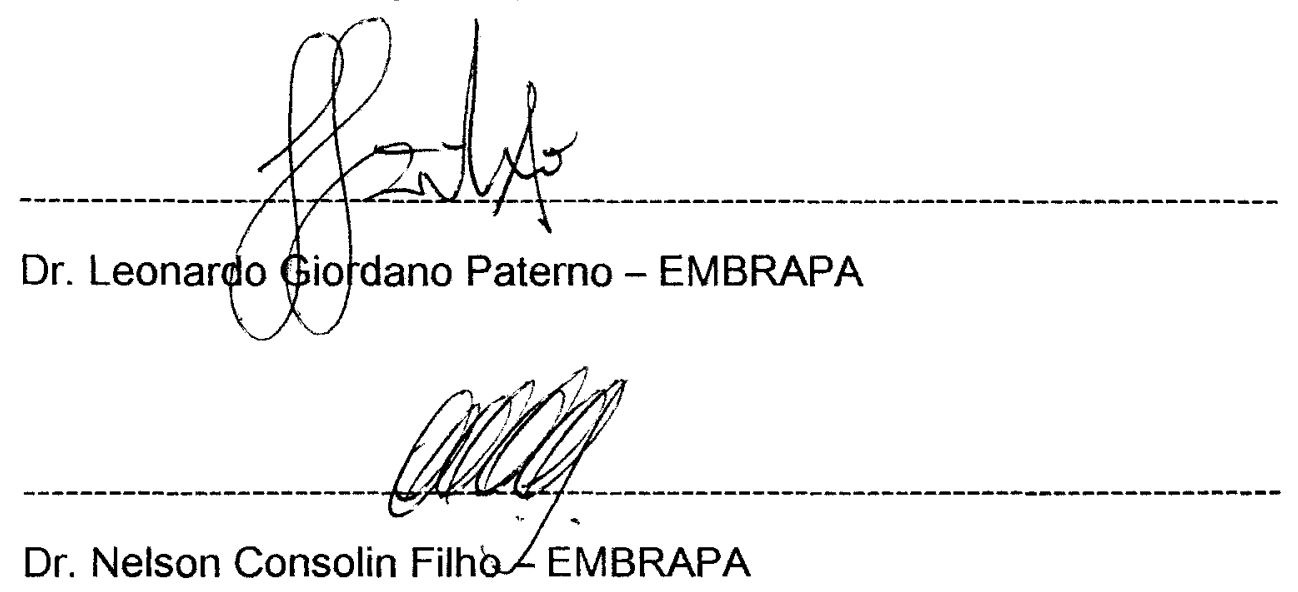
Dedico este trabalho aos meus pais, Ciro e Ivete, pelo amor, carinho, confiança e esforços que jamais foram medidos para mais essa conquista. Ao meu avô Tomio e a minha avó (in memória) Matsuko pelo seus carinhos e grandes lições ensinadas. As minhas queridas irmãs Karen e Monique e a minha tia Janete pelo eterno carinho, amor e por sempre estarem me dando forças para essa difícil caminhada pela Terra. 
A todos os moradores e ex-moradores da república que me acolheram, Nelson, Zé Fernando, Rogério, Sartori, Wendell, Moacir, Marcelo, Foca, Murilo, Daniel e Edson. A Dannan, Bethoven, Titico e Bino pelas horas de descontração. A todos os meus amigos e amigas, Priscila Curti, Sonia, Digão, Juliano, Leandro, Marquinhos, Luciano, Robertão, Ederval, Rúbia, Patrícia, Fernanda, Rafaela e a todos outros mais, pela amizade e companherismo.

Aos amigos que conheci aqui em São Carlos, Marcão, Carla, Oldair, Luci, Eduardo, Marcos, André, Tania, Juliana Barreiro, Juliana Manieri, Érica, Priscila, Nadja, Giuliane, Aline Laura, Gustavo, Alessandra Correa, Vivien, Tatiana, Larissa, Marcilene, Maria Alice e todos os outros da Embrapa, pela confiança e a amizade.

Aos funcionários da Embrapa pela valiosa ajuda, Rene, Ferrazini, Dr. Wilson, Alessandra, Marcelo e a todos os outros que muito me ajudaram.

Aos que no momento não me lembro peço desculpas, mas recebam meus honrosos e eternos agradecimentos. 
Que Deus não permita que eu perca o ROMANTISMO.

mesmo eu sabendo que as rosas não falam.

Que eu não perca o OTIMISMO,

mesmo sabendo que o futuro que nos espera não é assim tão alegre

Que eu não perca a VONTADE DE VIVER,

mesmo sabendo que a vida é, em muitos momentos, dolorosa..

Que eu não perca a vontade de TER GRANDES AMIGOS,

mesmo sabendo que, com as voltas do mundo,

eles acabam indo embora de nossas vidas...

Que eu não perca a vontade de AJUDAR AS PESSOAS.

mesmo sabendo que muitas delas são incapazes de ver.

reconhecer e retribuir esta ajuda.

Que eu não perca o EQUILIBRIO,

mesmo sabendo que inúmeras forças querem que eu caia

Que eu não perca a VONTADE DE AMAR,

mesmo sabendo que a pessoa que eu mais amo.

pode não sentir o mesmo sentimento por mim...

Que eu não perca a LUZ e o BRILHO NO OLHAR,

mesmo sabendo que muitas coisas que verei no mundo,

escurecerão meus olhos...

Que eu não perca a GARRA,

mesmo sabendo que a derrota e a perda

são dois adversários extremamente perigosos.

Que eu não perca a RAZ̃̃O,

mesmo sabendo que as tentações da vida são inúmeras e deliciosas.

Que eu não perca o SENTIMENTO DE JUSTIÇA,

mesmo sabendo que o prejudicado possa ser eu.

Que eu não perca o meu FORTE ABRAÇO,

mesmo sabendo que um dia meus braços estarão fracos...

Que eu não perca a BELEZA E A ALEGRIA DE VER,

mesmo sabendo que muitas lágrimas brotarão dos meus olhos

e escorrerão por minha alma...

Que eu não perca o AMOR POR MINHA FAMILIA,

mesmo sabendo que ela muitas vezes me exigiria

esforços incriveis para manter a sua harmonia.

Que eu não perca a vontade de DOAR ESTE ENORME AMOR que existe em meu coração,

mesmo sabendo que muitas vezes ele será submetido e até rejeitado.

Que eu não perca a vontade de SER GRANDE,

mesmo sabendo que o mundo é pequeno...

E acima de tudo...

Que eu jamais me esqueça que Deus me ama infinitamente,

que um pequeno grão de alegria e esperança dentro de cada um

é capaz de mudar e transformar qualquer coisa, pois....

A VIDA É CONSTRUÍDA NOS SONHOS

E CONCRETIZADA NO AMOR!

Amorosamente,

Francisco Cândido Xavier 


\section{Publicações em Anais}

TAKEDA, H. H.; FIRMINO, A.; MATTOSO, L. H. C. (2003). "Língua Eletrônica para a Diferenciação de Paladares Doce, Salgado, Azedo e Amargo" . In: IV SICEM - Simposio em Ciências e Engenharia de Materiais do Programa de Pós Graduação Interunidades, Universidade de São Paulo - Escola de Engenharia de São Carlos, São Carlos-SP.

TAKEDA, H. H.; FIRMINO, A.; Jr. RIUL, A.; FONSECA, F. J.; MATTOSO, L. H. C. (2003). "Língua Eletrônica para a Diferenciação de Paladares Doce, Salgado, Azedo e Amargo" . In: 5 Simpósio Latino Americano de Ciências de Alimentos, Unicamp, Campinas-SP

TAKEDA, H. H.; PATERNO, L. G.; FIRMINO A.; MATTOSO, L. H. C. (2004). "Layer by Layer Film of Poly(o-ethoxyaniline) Doped with Dodecylbenzenesulfonic Acid". In: Brazilian MRS Meeting 2004 - III Encontro da SBPMAT - Sociedade Brasileira de Pesquisa em Materiais, Foz do Iguaçu-PR.

\section{PRÊMIO RECEBIDO}

Menção Honroso pelo trabalho "Língua Eletrônica para a Diferenciação de Paladares Doce, Salgado, Azedo e Amargo" . In: $5^{\text {O }}$ Simpósio Latino Americano de Ciências de Alimentos, Unicamp, Campinas-SP 


\section{ÍNDICE}

LISTA DE FIGURAS.

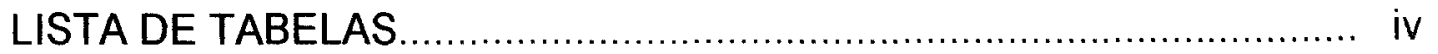

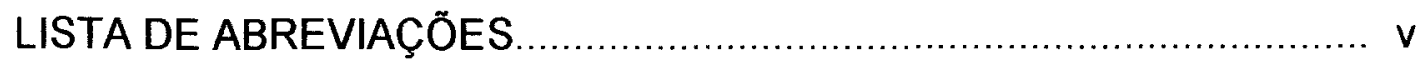

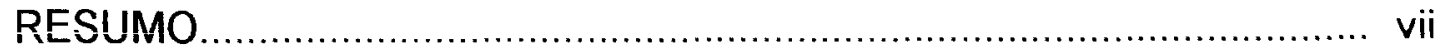

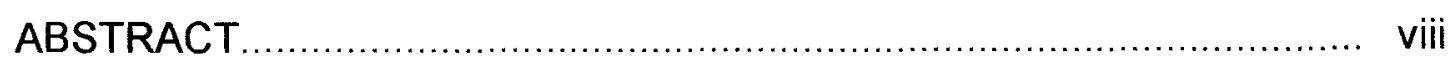

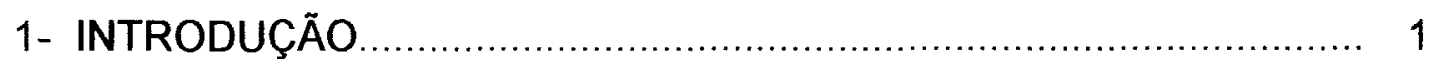

2- REVISÃO DA LITERATURA ....................................................... 3

2.1- Polímeros Condutores ......................................................... 3

2.2- História e Conceitos Básicos.................................................... 4

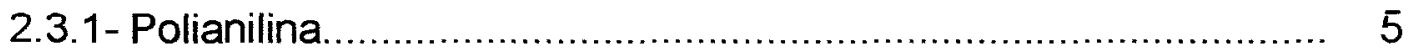

2.3.2-Síntese Química da Polianilina............................................... 6

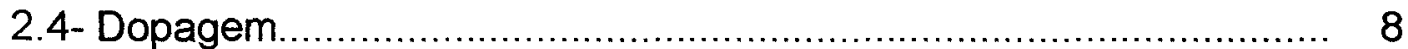

2.5- Adsorção e Filmes Poliméricos Ultrafinos..................................... 10

2.6. Sensores Medidas Elétricas...................................................... 15

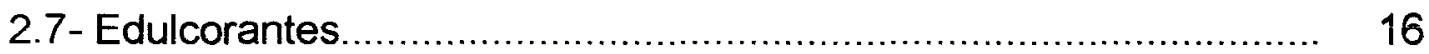

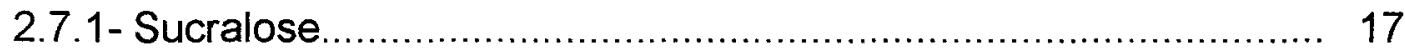

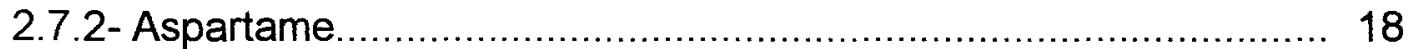

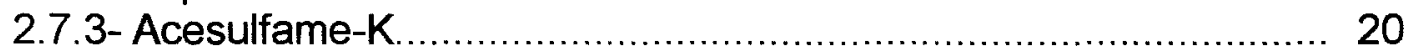

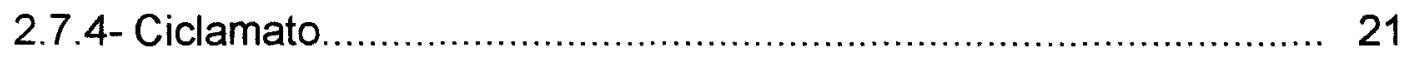

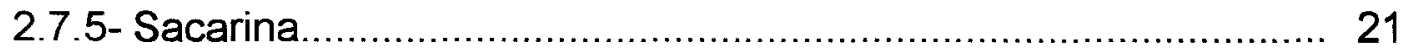

3- METODOLOGIA

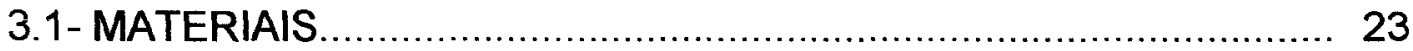

3.1.1- Polimeros e Dopantes..................................................... 23

3.1.2- Obtenção da POEA Dopada com Ácido Dodecilbenzenosulfônico (POEA-ADBS) .............................................. 25

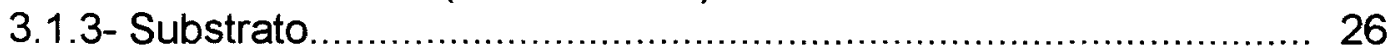

3.1.4- Microeletrodos Interdigitados ................................................... 26

3.1.5- Soluções Utilizadas para as Medidas da Lingua Eletrônica....... 27

3.2- Métodos................................................................................ 30

3.2.1- Fabricação dos Filmes por Automontagem............................. 30

3.2.2- Caracterização dos Filmes por Espectroscopia de UV-VIS......... 31

3.2.3- Microscopia de Força Atômica (AFM) ................................... 32

3.2.4- Filmes Utilizados para a Montagem da Língua Eletrônica.......... 33

3.2.5- Medida Elétricas da Língua Eletrônica (Espectroscopia de Impedância) ............................................................................. 33

4- RESULTADOS E DISCUSSÖES ................................................. 35 
4.1- Filmes de POEA ....................................................................... 35

4.2- Obtenção de Filmes de POEA Dopada com ADBS ......................... 44

4.3- Estudo da Morfolgia dos Filmes por AFM ...................................... 53

4.4- Medidas Elétricas.................................................................. 56

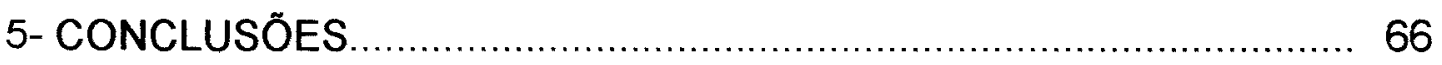

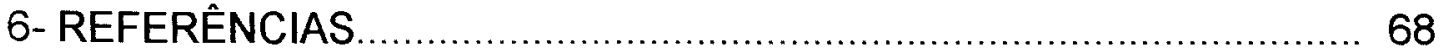




\section{LISTA DE FIGURAS}

Figura 1- Estrutura molecular da PANI no estado desprotonada........

Figura 2- Mecanismo de dopagem da PANI [41]. EB=Base esmeraldina; $\quad E S=$ sal de hidrocloreto de esmeraldina.

Figura 3- Método de automontagem via adsorção quimica. (a)filmes constituídos de camadas de 1,10-decanodilbisfosfonato de zircônio; (b)- filmes constituído de camadas de organosilanos.

Figura 4- Esquema de formação de filmes automontados proposto por Decher e

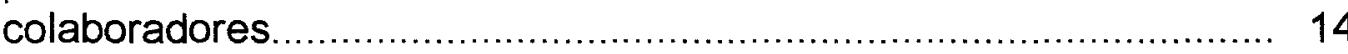

Figura 5- Estrutura química da sucralose ...................................... 18

Figura 6- Estrutura quimica do aspartame ...................................... 19

Figura 7- Estrutura química do acesulfame-k ............................... 20

Figura 8- Estrutura química do ciclamato....................................... 21

Figura 9- Estrutura química da sacarina ........................................... 22

Figura 10- Estrutura química da POEA na forma dopada. Os contra íons foram omitidos.

Figura 11- Estrutura química do poli(estirenosulfonato de sódio) (PSS).

Figura 12- (a) estrutura química do DBSS; (b) estrutura molecular do ADBS

Figura 13- llustração simplificada de um microeletrodo interdigitado contendo 5 dígitos. a) Vista frontal; b) Vista lateral: microeletrodo recoberto com filme polimérico com descrição das dimensões.

Figura 14- Espectro de UV-vis de soluções de POEA na concentração $0,04 \mathrm{~g} / \mathrm{L}$, dopadas comHCl em diferentes $\mathrm{pH}$ 's

Figura 15- Variação da absorbância de um filme de POEA em função do número de camadas adsorvidas. Solução de POEA a $1 \times 10^{-3} \mathrm{M}$ em pH 5 
Figura 16- Espectro de UV-VIS da décima camada de POEA com concentração de $1 \times 10^{-3} \mathrm{M}$ e pH 5 .

Figura 17- Variação da absorbância de um filme de POEA alternado com PSS em função do número de camadas adsorvidas. Solução de POEA e PSS a $1 \times 10^{-3} \mathrm{M}$ em $\mathrm{pH} 5$.

Figura 18- UV-VIS da décima bi camada POEA/PSS em pH 5 e com concentrações de $1 \times 10^{-3} \mathrm{M}$.

Figura 19- Variação da absorbância de filmes POEA alternado com DBSS e ADBS, todos em pH 5 e concentração de $1 \times 10^{-3} \mathrm{M}$.

Figura 20- Espectros de UV-VIS da décima bicamada para comparação de dopagem e formação de filmes alternados de POEA com DBSS e ADBS em pH5 e concentração de $1 \times 10^{-3} \mathrm{M}$ para todas as soluções.

Figura 21- Espectros de UV-VIS da décima bicamada de POEA/DBSS E POEA/PSS

Figura 22- Espectros de UV-VIS para a formação de complexo e dopagem da POEA-DBSS (solução aquosa) em pH's 3 e 5 e concentrações de $5 \times 10^{-5} \mathrm{M}$ e $1 \times 10^{-4} \mathrm{M}$ para solução de POEA e DBSS respectivamente.

Figura 23- Gráfico de UV-VIS das soluções aquosas de POEAADBS e POEA com concentrações de $5 \times 10^{-5} \mathrm{M}$ e $1 \times 10^{-4} \mathrm{M}$ para a POEA e o ADBS respectivamente e $\mathrm{pH} 3$ e 5 .

Figura 24- UV-VIS dos complexos (solução aquosa) POEA-NaCl em pH's 3 e 5 . A concentração da POEA é $5 \times 10^{-5} \mathrm{M}$ e para o $\mathrm{NaCl}$ $1 \times 10^{-1} \mathrm{M}$.

Figura 25- Espectros de UV-VIS para o estudo de dopagem da POEA EB com ADBS.

Figura 26- Evolução da absorbância em função do número de camadas de POEA dopada com ADBS com concentração de $1,85 \times 10^{-4} \mathrm{M}$ e pH 3,25 (solvente DMAC $+\mathrm{H}_{2} \mathrm{O}$ ).

Figura 27- (a) imagem 3D de filmes contendo 5 camadas de POEAADBS em pH 3,25 e (b) imagem de 5 bicamadas de POEAADBS/PSS em pH 3,25 (solvente DMAC $+\mathrm{H}_{2} \mathrm{O}$ ) (c) Perfil topográfico dos filmes estudados. 
Figura 28- Gráfico de respostas de medidas de capâcitancia para cada tipo de paladar e água destilada

Figura 29- PCA para água destilada e paladares doce, azedo e salgado.

Fugura 30- PCA das soluções de edulcorantes e sacarose, realizadas em três dias consecutivos. 


\section{LISTA DE TABELAS}

Tabela I- Edulcorantes, combinações de edulcorantes e sacarose com suas respectivas concentrações utilizadas para medidas com a Língua Eletrônica.

Tabela II- Nome dos fabricantes dos edulcorantes e sacarose utilizada para as medidas com a língua eletrônica. 28

Tabela III- Filmes fabricados por automontagem. 30

Tabela IV- Filmes utilizados para a fabricação da língua eletrônica....

Tabela V- Valores característicos de comprimento de ondas para sistemas dopados com ácidos sulfonicos funcionalizados

Tabela VI- Valores de capacitância em $1 \mathrm{KHz}$ para os eletrodos antes e após deposição de filmes poliméricos.

Tabela VII- Valores das melhores freqüências de trabalho para cada eletrodo.

Tabela VIII- Edulcorantes, combinações de edulcorantes e sacarose com suas respectivas concentrações utilizadas para medidas com a Língua Eletrônica. 


\section{LISTA DE ABREVIAÇÕES}

ADBS: Ácido dodecilbenzenosulfonico

AFM: Microscopia de Força Atômica

AC: Corrente alternada

DBSS: Dodecilbenzenosulfonato de sódio

ES: Hidrocloreto de esmeraldina

GPC: Cromatografia de permeação em gel

IDA: Ingestão diária aceitável

LB: Langmuir-Blodgett

PANI: Polianilina

POEA: Poli(o-etoxianilina)

POEA-EB: Poli(o-etoxianilina) base esmeraldina

POEA-ES: Poli(o-etoxianilina) sal de esmeraldina

POEA-ADBS: Poli(o-etoxianilina) dopada com ácido

dodecilbenzenoosulfônico

PCA- Análise de Componentes Principais

PVC: poli(cloreto de vinila)

PSS: Poli(estirenosulfonato) de sódio

PTTA: Poli(tiofeno-3-ácido acético)

POMA: Poli(o-metoxianilina)

PVS: Poli(vinil sulfato de sódio)

RMS: Rugosidade Média Quadrática 
SPAn: Poli(anilina sulfonada)

UV-VIS: Ultra Violeta Visível 


\section{RESUMO}

A Embrapa Instrumentação Agropecuária tem se dedicado ao desenvolvimento de metodologias, instrumentos, materiais, sensores, automação e tecnologias relacionadas a instrumentação, que contribuam para a melhoria da competência e sustentabilidade do agronegócio brasileiro è preservação do meio ambiente, temas de extrema importância para o país. Neste contexto o objetivo deste trabalho foi a preparação e o estudo de novos materiais, visando a sua aplicação em sensores do tipo língua eletrônica. Para isso, foram necessários estudos de combinações de polímero condutor e dopantes. Filmes ultra-finos foram depositados pela técnica de automontagem e estudados por medidas de Ultra Violeta Visivel (UV-VIS), onde verificou-se uma mesma contribuição de material depositado a cada imersão do substrato realizada e também a dopagem dos filmes em certas condições de deposição da solução de poli(o-etoxianilina) (POEA). Utilizando-se POEA alternada com dodecilbenzenosulfonato de sódio (DBSS), poli(estirenosulfonato) de sódio (PSS) e ácido dodecilbenzenosulfônico (ADBS) em pH 5, observou-se a dopagem do filme de POEA, através do aparecimento da banda polarônica devido ao deslocamento do equilíbrio de Donnan. Para a dopagem das soluções de POEA utilizando-se ADBS, DBSS e $\mathrm{NaCl}$, verificou-se a dopagem das soluções tanto para pH 5 como para pH 3, com exceção do $\mathrm{NaCl}$ em pH 3 . No entanto, com essas soluções não conseguiu-se a formação de filmes pố automontagem sendo necessário a utilização de uma solução de POEA-EB contendo $20 \%$ de solvente orgânico dimetil acetamida (DMAC), dopante (ADBS) e $80 \%$ de água em pH 3,25. Por medidas de UV-VIS, observou-se a dopagem dessa solução, devido ao aparecimento da banda polarônica acima de $800 \mathrm{~nm}$. Sendo assim, estudou a formação de filmes utilizando essa nova solução, onde verificou-se que há uma mesma contribuição de material depositado no substrato a cada imersão realizada. Para a montagem da língua eletrônica todos os filmes foram depositados por automontagem em eletrodos interdigitados de ouro. Através de medidas de capacitância foram analisadas soluções dos paladares padrões, ácido clorídrico para paladar azedo, sacarose para doce, cloreto de sódio para salgado e água destilada e com os resultados obtidos foi realizado a análise de componentes principais (PCA) onde verificouse uma boa capacidade da língua eletrônica em destinguir os diferentes paladares e a água destilada. Após essas medidas, foram analisadas combinações de edulcorantes em solução e através do PCA e observou-se também uma boa capacidade da língua eletrônica em destinguir os diferentes edulcorantes. 


\begin{abstract}
Embrapa Agricultural Instrumentation Center has been dedicated to the development of methodologies, instruments, materials, sensors, automation and technology related to instrumentation that contributes to the improvement of Brazilian agrobusiness and to environmental preservation, which are extremely important to our country. In this sense, the aim of this work was the preparation and study of novel materials for application in an electronic sensor system. For that, it was necessary to study films made up of combinations of conducting polymers and doping acids. Those films were deposited by the Layer-by-layer method and studied by UV-Vis spectroscopy (UV-Vis) and it was verified that a same amount of polymeric material was deposited onto the films after each immersion of the substrate into the polymeric solutions. By using POEA layers aliternated with sodium dodecylbenzene sulfonate (DBSS), sodium polysterene sulfonate (PSS) and dodecylbenzene sulfonic acid (ADBS) at pH 5 it was observed doping of the film due to the presence of the polaronic band around $800 \mathrm{~nm}$. The doping was attributed to protonation and shift on the Donnan equilibrium. However it was not possible to obtain films from these solution containing just water. In a different approach, POEA in its undoped state was dissolved in a mixture of dimethyl acetamide (DMAC), ADBS and ultra pure water at $\mathrm{pH} 3.25$, and films were deposited. According to UV-Vis data it was observed doping of POEA in this solution as well as in the film deposited. Different films were able to be produced from POEA which were selected and deposited onto interdigitated microelectrodes in order to compose an electronic tongue. With this sensor system, solutions containing different tastes: sour $(\mathrm{HCl})$, sweet (sucrose), salty $(\mathrm{NaCl})$ and ultra pure water were analyzed by electrical capacitance measurements. Solutions containing commercial sweeteners were also analyzed by this electronic tongue. The experimental results have showed that the electronic tongue composed of ultra thin films of POEA doped with different acids was able to distinguish among solutions containing different tastes indicating its potentiality for liquid analysis.
\end{abstract}




\section{1- Introdução}

Língua Eletrônica é um tipo de sensor utilizado para análise em líquidos. Três tipos de línguas eletrônicas são relatadas na literatura. A primeira é constituida de lipídios dispersos em poli(cloreto de vinila) PVC [1-3], a segunda é feita de vidros calcogênicos [4-7] e a desenvolvida pela Embrapa usam-se polímeros condutores combinados com materiais sensiveis fazendo com que um mesmo polímero condutor apresente diferentes respostas elétricas para um mesmo tipo de líquido, criando assim uma impressão digital.

As principais qualidades requeridas na língua eletrônica, são alta sensibilidade, estabilidade e seletividade. O tipo de polímero condutor utilizado, combinação com outros materiais sensiveis e tipos de dopantes, são variáveis que influenciam muito nas qualidades citadas acima, sendo portanto, de grande importância o estudo dessas variáveis.

O funcionamento da língua eletrônica, baseia-se no da língua humana, ou seja, sua função é conseguir um padrão de resposta do sabor e não identificar separadamente a substâncias presentes na bebida. Esse conceito é conhecido por seletividade global, e implica na habilidade de classificar grandes quantidades de substâncias em diferentes grupos, como o realizado pelos sistemas biológicos. Desta forma, sensores tem sido utilizados para imitar a funç̧ão de alguns sistemas biológicos, como os atuais sensores olfativos (também conhecidos por narizes eletrônicos) encontrados na literatura [8-14].

Línguas eletrônicas, têm sido desenvolvidas para serem utilizadas em controle de qualidade de bebidas, como por exemplo, água mineral, cafés e vinhos $[15-17]$ 
Neste trabalho estudou-se um novo sistema, o ácido dodecilbenzenosulfônico como dopante para a poli(o-etoxianilina) (POEA) e combinações com o poli(estirenosulfonato) (PSS) para a preparação de filmes automontados visando a aplicação em um sistema sensor para a avaliação de sacarose e edulcorantes. 


\section{2- REVISÃO DA LITERATURA}

\section{1- Polímeros Condutores}

Os polímeros condutores têm atraído o interesse de vários grupos de pesquisa no mundo [18], devido à sua capacidade de combinar as propriedades comuns de sistemas poliméricos com propriedades de materiais metálicos e inorgânicos, tais como condutividade elétrica, eletrocromismo e eletroluminescência. Além disso são materiais de fácil obtenção, térmica e quimicamente estáveis e podem ser dopados de maneira controlada. Devido a essas propriedades, os polímeros condutores têm sido aplicados para $\circ$ desenvolvimento de baterias recarregáveis, dispositivos eletrônicos, sensores químicos e térmicos, biosensores, janelas inteligentes, diodos emissores de luz, eliminação de carga estática em microeletrônica, proteção contra corrosão, revestimento de materiais, etc. [19-35].

Um critério importante na seleção de polímeros condutores é a facilidade de dopagem. Isto leva a escolha de polímeros conjugados, que possuam baixo potencial de oxidação. Os elétrons de caráter $\pi$ podem ser facilmente removidos para formar um ion polimérico, sem a destruição das ligações necessárias para a estabilidade da macromolécula [18].

Este princípio básico tem sido aplicado com sucesso para um número crescente de polímeros conjugados [20,36], tais como polifenilenos, polipirróis, politiofenos e polianilinas. O poliacetileno ainda é o polímero que tem alcançado o maior valor de condutividade $\left(10^{4} \mathrm{~S} / \mathrm{cm}\right)[36,37]$ igualando-se ao cobre. No entanto pelas dificuldades como a instabilidade térmica e ambiental e 
improcessabilidade (insolubilidade e infusibilidade) do mesmo, outros polímeros conjugados têm sido pesquisados com objetivos de superar estas dificuldades [18].

A polianilina (PANI) e seus derivados têm ganhado destaque devido a sua estabilidade química em condições ambientais, processabilidade, facilidade de polimerização e dopagem e baixo custo. Essas vantagens tornam viáveis em aplicações tecnológicas [27-30]. Nos últimos anos, houve um grande avanço na compreensão química, eletroquímica, estruturais, fenômenos elétricos e óticos, processamento e aplicações da polianilinas e seus derivados [38].

\section{2- História e Conceitos Básicos}

A princípio, os materiais poliméricos são isolantes elétricos devido a suas ligações químicas covalentes [39]. O primeiro polímero intrinsecamente condutor foi obtido em 1977 [37]. Shirakawa e colaboradores através da exposição do poliacetileno na forma isolante (condutividade $\sigma=10^{-8} \mathrm{~S} / \mathrm{cm}$ ) a agentes dopantes, tornando-o condutor $\left(\sigma=10^{4} \mathrm{~S} / \mathrm{cm}\right)$ [37]. O polímero neutro isolante é convertido em um complexo iônico, que consiste de um cátion (ou ânion) polimérico e um contraíon que é a forma reduzida do agente oxidante (ou a forma oxidada do agente redutor) [37]. Segundo os autores, a condutividade é originada no processo de oxidação das ligações químicas da cadeia principal do polímero, o que gera defeitos estruturais, ou seja, cargas deslocalizadas que podem se movimentar pelo polímero, levando a conseqüente condução elétrica. 


\subsection{1- Polianilina}

A PANI é o polímero conjugado mas antigo que se tem notícia. No início da sua descoberta pouco se sabia a seu respeito, mas na metade de 1980 , houve uma melhor caracterização deste material [35].

A PANI apresenta uma grande diferença na sua forma de dopagem em relação aos outros polímeros condutores [40-44]. A PANI base de esmeraldina pode ser dopada com um ácido protônico não oxidante e sem que ocorra mudança no número de elétrons associados a cadeia polimérica [45-47].

A utilização de soluções aquosas de ácidos, como por exemplo $\mathrm{HCl}$ $[40,41]$ com concentração $1,0 \mathrm{M}$ como dopante, provoca um aumento da condutividade em 10 ordens de grandeza, levando a forma do sal hidrocloreto de esmeraldina (ES) que se apresenta na cor verde. A condutividade deste material não se altera por um longo período de exposição ao ar [19]. A desprotonação ocorre por tratamento com solução aquosa básica $\left(\mathrm{NH}_{4} \mathrm{OH}\right.$ 0,1 M). Este grande aumento na condutividade da PANI utilizando-se ácidos protônicos é devido a adição de prótons ser mais eficiente do que a oxidação parcial do sistema $\pi$ do polímero como no caso de outros tipos de polímeros condutores [48]

A polianilina tem atingido uma condutividade da ordem de $10^{3} \mathrm{~S} / \mathrm{cm}$ para um polímero de alta massa molecular e uniaxialmente orientado [49].

A estrutura química da PANI, na forma não dopada, é dada por uma fórmula geral do tipo: 


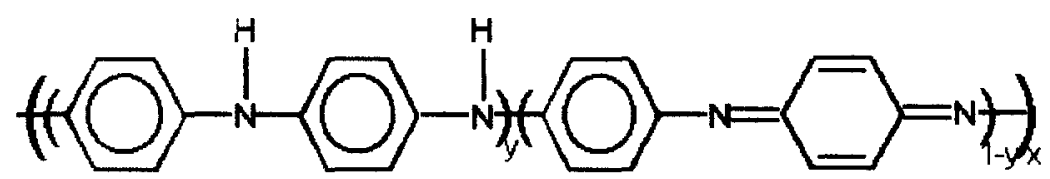

Figura 1- Estrutura química da PANI no estado desdopado [18]

composta por y e (1-y) unidades repetitivas das espécies reduzidas e oxidadas respectivamente. $\mathrm{O}$ valor de y pode variar continuamente entre 1 para 0 polímero completamente reduzido (contendo somente nitrogênios amina) e zero, no caso do polímero completamente oxidado (contendo apenas nitrogênios imina) [40]. Os diferentes graus de oxidação da polianilina são designados pelos termos leucoesmeraldina, protoesmeraldina, esmeraldina, nigranilina e pernigranilina quando $y$ for igual a $1 ; 0,75 ; 0,5 ; 0,21$ e 0 respectivamente [18]. Assim a condutividade da PANI depende do grau de oxidação e de protonação do material.

Este polímero poder ser obtido tanto por síntese química quanto por eletroquímica, conforme será descrito a seguir.

\subsection{2- Síntese Química da Polianilina}

A síntese química da PANI pode ser realizada com vários agentes oxidantes $\left(\left(\mathrm{NH}_{4}\right)_{2} \mathrm{~S}_{2} \mathrm{O}_{8}, \mathrm{MnO}_{2}, \mathrm{Cr}_{2} \mathrm{O}_{4}, \mathrm{H}_{2} \mathrm{O}_{2}, \mathrm{~K}_{2} \mathrm{Cr}_{2} \mathrm{O}_{7}\right.$ e $\left.\mathrm{KClO}_{3}\right)$ e meios ácidos $\left(\mathrm{HCl}, \mathrm{H}_{2} \mathrm{SO}_{4}, \mathrm{H}_{3} \mathrm{PO}_{4}, \mathrm{HCl}_{4}, \mathrm{HPF}_{6}\right.$, etc.), sendo o sistema mais comum o peroxidissulfato de amônio em soluções aquosas de $\mathrm{HCl}$ com pH entre 0 e 2 [49-51]. 
MacDiarmid et. al. [52] conseguiram obter uma polianilina com um porcentagem maior que $99 \%$ em pureza. Para isso utilizaram anilina em excesso, com uma razão molar agente oxidante por monômero igual a 0,25. Através deste método obtêm-se um precipitado verde escuro, que após excessiva caracterização foi classificada como sal de esmeraldina (ES), no qual $42 \%$ dos átomos de nitrogênio do polímero estão protonados, independentes de serem aminas ou iminas [51]. Com este método conseguiu-se chegar em um polímero condutor (não substituído) completamente solúvel em solventes orgânicos na forma de filmes e fibras por solução [52-54].

Através de dopantes e condições de reação pode-se dar características especificas para a polianilina. Como um exemplo, obtém-se polianilina de alta estabilidade térmica quando polimerizado em presença de ácido fosfórico $[55,56]$.

Pode-se produzir também um polímero de alta massa molecular e controlável. Para esta realização é necessário a adição de um sal inerte ao meio reacional, que blinda as cargas positivas dos sítios de crescimento da cadeia polimérica facilitando a aproximação e adição do monômero a cadeia em crescimento [57].

Pela síntese química tem-se a vantagem de se obter um polímero com alta massa molecular, alto grau de pureza e que já encontra-se no estado dopado $[20,36,37]$. A maior vantagem, porém é de se obter polímero em grandes quantidades. 


\section{4- Dopagem}

A dopagem é um conceito que faz a distinção dos polímeros condutores em relação aos outros polímeros. $\mathrm{Na}$ área de polímeros condutores, o dopante é uma substância, que em pequenas quantidades, muda drasticamente as propriedades estruturais, eletrônicas, ópticas, magnéticas e é acompanhado de um aumento na condutividade [58]. Há duas formas de dopagem de polímeros, uma delas é por redução ou oxidação dos elétrons ou da cadeia central do polímero, isto é, dopagem $\mathrm{p}$ ou $\mathrm{n}$ do $(\mathrm{CH})_{\mathrm{x}}$. A outra forma de dopagem é por meio de ácidos protônicos, de forma que não ocorra mudança no número de elétrons na cadeia polimérica [58].

Estudos de ressonância paramagnética eletrônica $[20,44]$ mostraram que - grau máximo de protonação da polianilina é de $50 \%$, e é fortemente paramagnética, e a susceptibilidade magnética de Pauli (independente da temperatura) aumenta linearmente com o grau de protonação. Com estes estudos ficou comprovado que a polianilina dopada é formada por cátions radicais de poli(semiquinona) $[41,44]$, originando assim uma banda de condução polarônica. A Figura 2 ilustra a um mecanismo de dopagem da PANI 


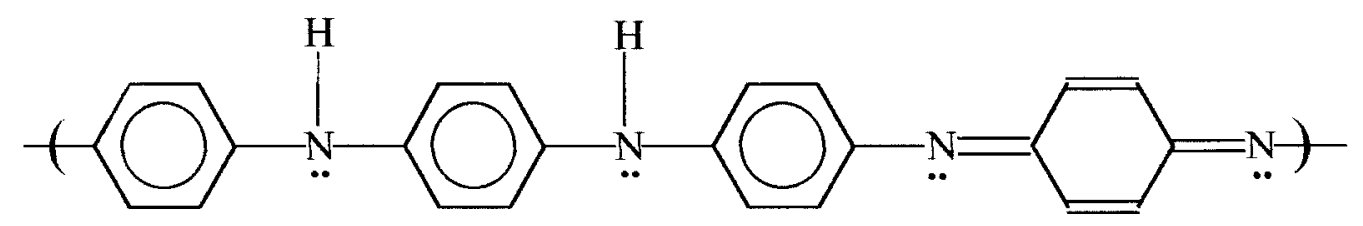

$\mathrm{HCl} 1,0 \mathrm{~mol} / \mathrm{L}$

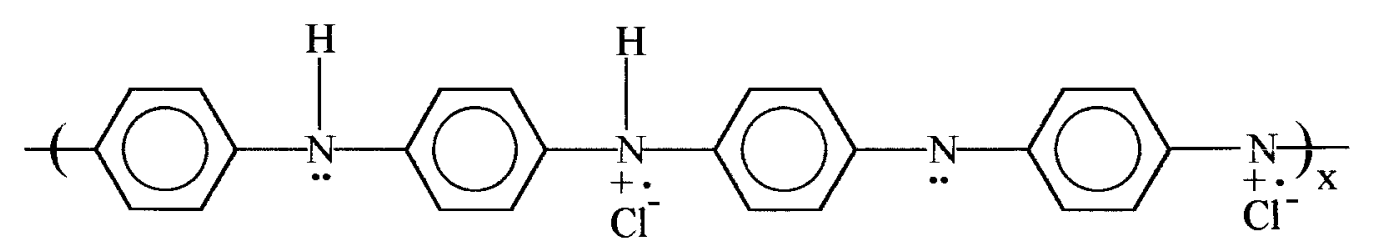

Figura 2- Mecanismo de dopagem da PANI [41]. EB=Base esmeraldina; $\mathrm{ES}=$ sal de hidrocloreto de esmeraldina.

Estudos [18] sugerem que a protonação da polianilina não é homogênea, mas que há a formação de domínios completamente protonados; que originam ilhas metálicas embebidas em regiões não protonada isolantes. Foi proposto que essas ithas são cadeias poliméricas condutoras e protonadas, onde ocorre a formação dos polarons.

As características desejadas para a polianilina dependem do tipo do dopante a ser utilizado, onde ocorre grande influência na sua estrutura e propriedades (solubilidade, cristalinidade, condutividade elétrica, resistência mecânica, etc) [18].

A polianilina pode sofrer um efeito de auto dopagem, quando se utiliza ácido sulfúrico concentrado. Neste caso, um átomo de hidrogênio do anel 
benzênico é substituído por um grupo $-\mathrm{SO}_{3} \mathrm{H}$, resultando em uma polianilina sulfonada dopada $(\sigma=0,1 \mathrm{~S} / \mathrm{cm})[18]$.

\section{5- Adsorção e Filmes Poliméricos Ultrafinos}

A adsorção de polímeros tem se tornado um assunto de interesse teórico e experimental. O comportamento de adsorção polimérica na interface sólidolíquido está fortemente ligado a importantes processos tecnológicos, como por exemplo, estabilização coloidal, floculação, adesão, revestimentos e lubrificação [59]. Hoje, um dos principais objetivos da adsorção de filmes poliméricos é a formação de filmes ultrafinos que apresentam aplicação potencial em ótica integrada, sensores, revestimento para a diminuição de atrito, agentes de superfície para orientação de camadas, e em dispositivos de heterojunções, como diodos emissores de luz $[60,61]$.

Langmuir, foi quem propôs o primeiro tipo de produção de filmes ultra finos, que ficou conhecido como Filmes de Langmuir [62], onde a formação de filmes ocorrea em uma subfase líquida. Mais tarde, Blodgett implementou o procedimento de Langmuir, sendo então, a técnica nomeada de Filmes de Langmuir-Blodgett (LB) [63]. A técnica LB, baseia-se na formação de camadas monomoleculares, usando-se geralmente ácidos graxos, sobre uma subfase aquosa, onde após a formação do filme, o mesmo é transferido para um substrato sólido desejado. Pode-se montar várias camadas de filmes, onde todos eles são organizados a nível nanométrico. Pode-se escolher a condição de deposição, o número de camadas e o tipo de material a ser depositado. 
Algumas vezes, a montagem dos filmes pode ser lenta, e também é necessário um ambiente de trabalho extremamente limpo e isolado, elevando assim o seu custo de montagem.

$\mathrm{Na}$ década de 1980, Sagiv e colaboradores. [64] demonstraram a possibilidade de formação de filmes compostos por monocamadas quimicamente adsorvidas entre si, de maneira diferente a proposta por LB. Este método consiste na imersão de um substrato sólido em uma solução contendo moléculas bifuncionais, como fosfatos metálicos e organosilanos. Estes materiais podem ser imobilizados através da formação de ligações covalentes com o substrato, o que os mantém fortemente adsorvidos. A Figura 3 (a), ilustra este tipo de formação de filmes. Devido a bifuncionalidade da molécula, a extremidade que não se liga ao substrato, serve de conexão para uma outra monocamada, permitindo desta forma, a formação de multicamadas.

As forças de interações envolvidas nesta técnica são ligações de hidrogênio, força de Van der Walls, forças dispersivas ou de London, dando uma forte adsorção e uma boa compactação do filme sobre o substrato [60].

No caso particular dos organosilanos, devido a presença de moléculas de água, pode haver a formação de redes de ligações covalentes do tipo Si-O$\mathrm{Si}$, entre as molécula adjacentes da monocamada. Esta formação dá um caráter de uma rede tridimencional do polímeros, proporcionando uma grande estabilidade ao filme. A Figura 3 (b), ilustra a rede de silanos.

A grande desvantagem desta técnica é a necessidade de reações com alto rendimento (teoricamente $100 \%$ ), além disso a interferência de impurezas, 
faz com que ocorra diminuição de sítios de adsorção, ocasionando assim, defeitos nos filmes e interrupção do processo.

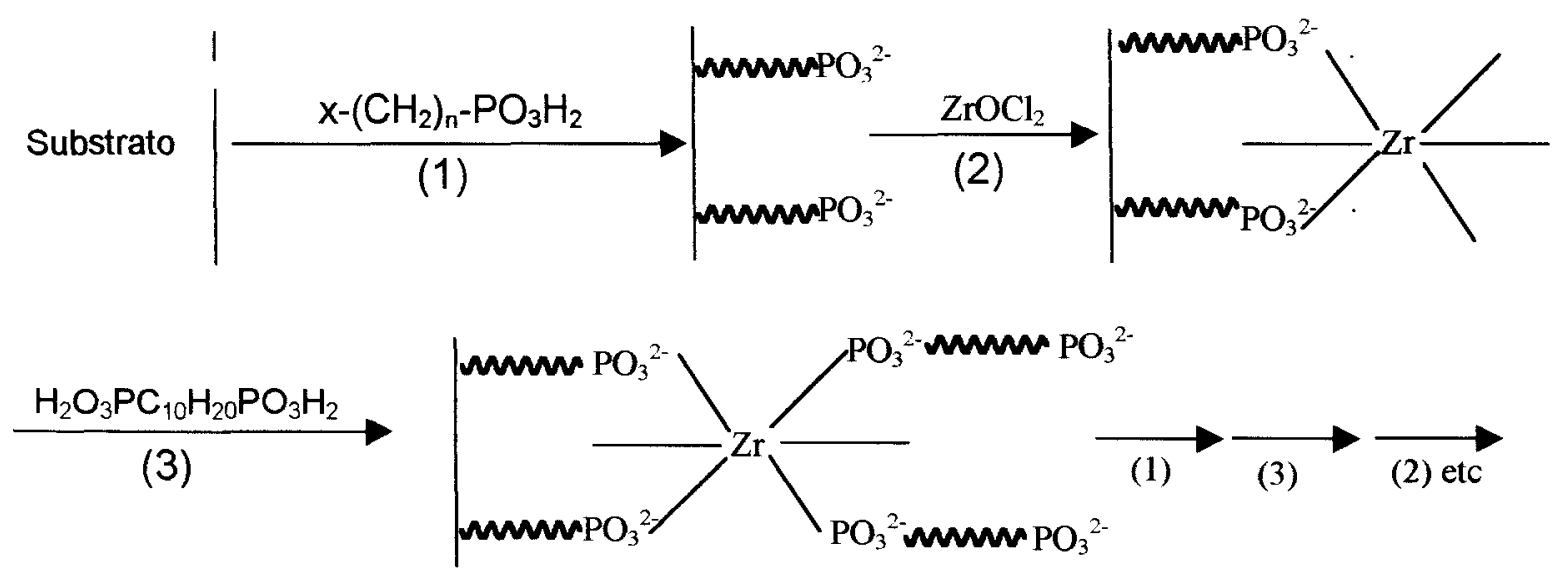

(a)

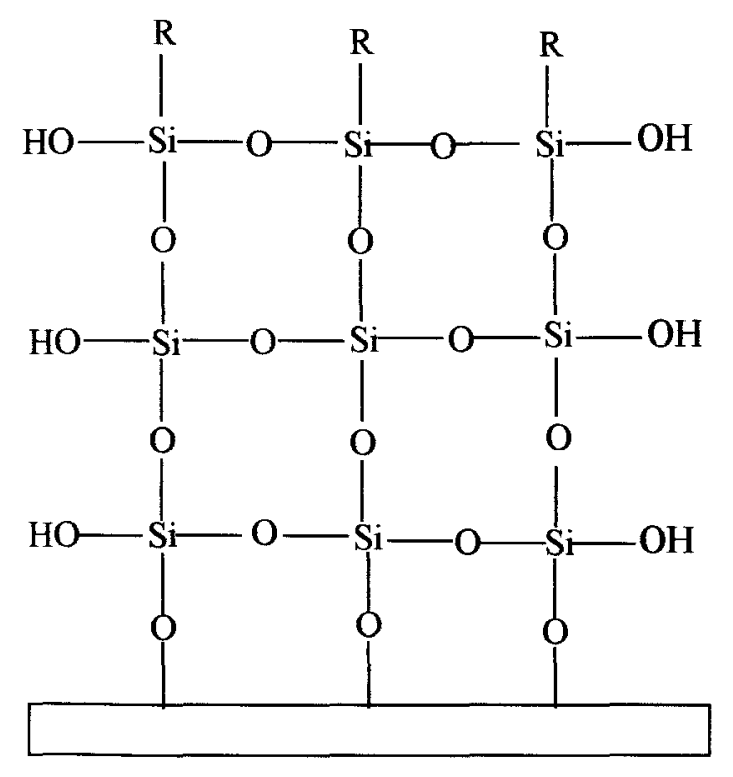

(b)

Figura 3- Método de automontagem via adsorção química. (a)- filmes constituidos de camadas de 1,10-decanodilbisfosfonato de zircônio; (b)filmes constituído de camadas de organosilanos [65]. 
Na década de 1990, Decher e colaboradores [66], propuseram uma nova maneira de adsorçcão de filmes ultra finos, a qual foi nomeada de Self Assembly (automontagem). A técnica baseia-se na formação de filmes via atração eletrostática, onde um substrato sólido é imerso em uma solução de um policátion e em seguida é imerso em uma solução de um poliânion. A Figura 4 ilustra como ocorre a formação das camadas automontadas. A bicamada formada possui uma espessura variando entre 10-100 $\AA$. Essa espessura pode ser ajustada de acordo com a concentração, pH e força iônica das soluções envolvidas.

A grande vantagem desta técnica é que ela permite a formação de várias camadas sobrepostas e procedimentos menos complexos do que a técnica LB e menor custo.

Através da técnica de espectroscopia de UV-VIS, Decher e colaboradores [54], verificaram que ocorre um crescimento linear na absorbância dos filmes formados. Com esses resultados chegou-se a conclusão que a cada imersão, ocorre um depósito controlado do filme, isto é, sempre há deposição de uma mesma quantidade de material sobre o substrato [66]. 


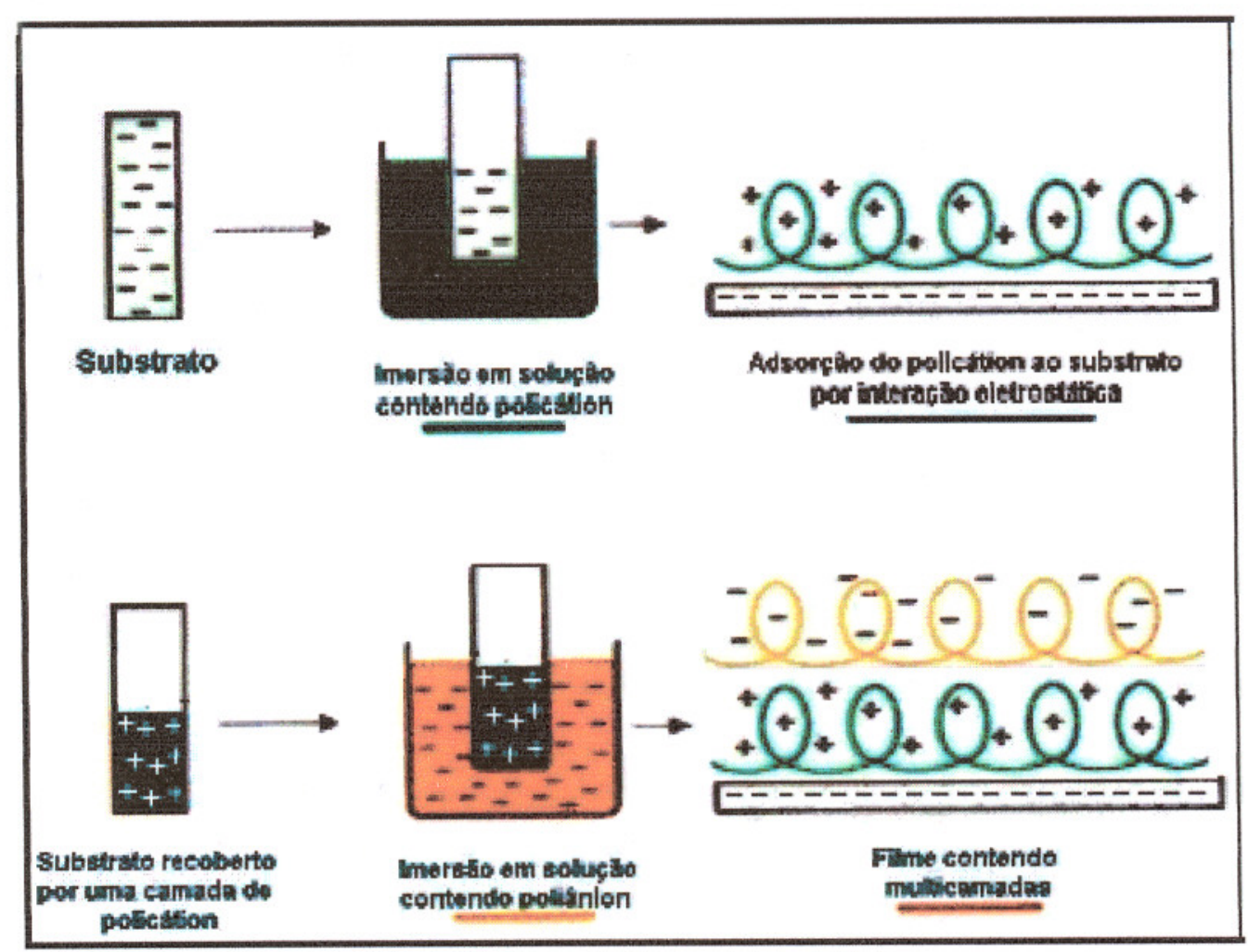

Figura 4- Esquema de formação de filmes automontados proposto por Decher e colaboradores [66].

Os primeiros filmes ultrafinos de polímeros condutores utilizando a técnica de automontagem, foram fabricados por Rubner e colaboradores [67]. Em seu trabalho, Rubner e colaboradores [67] pesquisou várias combinações de polímeros condutores, principalmente combinações de poli(anilina sulfonada) (SPAn) e poli(tiofeno-3-ácido acético) (PTTA) com hidrocloreto de polianilina [68-69] (os filmes obtidos a partir destes polímeros apresentaram homogeneidade e a espessura dos filmes obtido com essas combinações foram 
de 200 e 300 A). A espessura dos filmes pode ser controlada pelo número de camadas depositadas. A condutividade de um filme contendo 15 camadas de SPAn dopado com $\mathrm{HCl}$ foi da ordem de $10^{-3} \mathrm{~S} / \mathrm{cm}$. No grupo de pesquisa da Embrapa Instrumentação Agropecuária tem se estudado muito sobre a formação de filmes pela técnica de automontagem onde vem se obtendo bons resultados $[70,71,72,73]$

\section{6- Sensores e Medidas Elétricas}

Existem vários estudos sobre sensores, conhecidos como línguas eletrônicas [15, 17, 75-77], um instrumento de grande importância que futuramente poderá ser aplicado nas indústrias alimentícias.

Línguas Eletrônicas com seletividade global, são compostas por vários tipos de materiais sensíveis/polímeros para a transformação de informação do sabor da substância em sinal elétrico [77]. Já na língua humana, substâncias são detectadas em uma membrana biológica composta principalmente de lipídios e proteinas, localizada em canais especiais na língua. As informações trazidas pelas diferentes substâncias são transformadas em sinais elétricos que são transmitidos pelos nervos ao cérebro, onde o gosto é identificado.

O funcionamento deste sensor desenvolvido na Embrapa, está baseado na espectroscopia de impedância, pois umas das grande vantagens apresentada por essa técnica é a não utilização de um eletrodo de referência, como ocorre em medidas de potenciometria ou voltametria [78].

Os dados obtidos pela espectroscopia de impedância são divididos em duas categorias, os que estão relacionados somente com o próprio material 
depositado sobre o eletrodo, como a condutividade, mobilidade de cargas, concentrações de equilíbrio de espécies carregadas e velocidades de geraçãorecombinação de cargas no volume do material, e segundo os relacionados à interface do material depositado no eletrodo, como as constantes de velocidade de reação de adsorção, velocidade de transporte de cargas, capacitância da região de interface e coeficientes de difusão [79]. Outros sensores encontrados na literatura usam medidas elétricas de voltametria, potenciometria e condutividade ou ainda uma combinação dessas medidas [76].

\section{7- Edulcorantes}

O aumento da população mundial provocou uma necessidade no aumento da produção de alimentos sem que haja, se possível, a perda da qualidade. Uma saída para este problema é a utilização de aditivos para uma melhor e maior durabilidade do alimento industrializado [80]. Segundo a Organização das Nações Unidas de Alimento e Agricultura, aditivos são substâncias não nutritivas que conferem ao alimento uma melhora em sua aparência, textura, sabor e tempo de armazenagem [81].

Dentre os aditivos, encontra-se os edulcorantes, também conhecidos como adoçantes artificiais, que possuem a capacidade de dar ao alimento um sabor doce.

Os adoçantes artificiais têm sido muito utilizados na substituição da sacarose em alimentos para diabéticos por aumentar a taxa de glicose no sangue e em dietas de pessoas obesas, devido sua conversão em lipídios, causando assim um aumento do peso do consumidor [80]. Um adoçante 
artificial ideal deve ser incolor e inodoro em solução, estável e solúvel em soluções aquosas, atóxico, barato, não deixar sabor residual e não ser metabolizado ou produzir metabólitos que prejudiquem o organismo [82].

Além de produtos dietéticos, os adoçantes artificiais são utilizados também em remédios para mascarar as características organolépticas dos fármacos e em produtos de higiene bucal para diminuir a incidência de cáries nos usuários, pois não são metabolizadas pelas bactérias (e.g.Streptococus mutans, Lactobacillus casei, Actnomyces viscosus), geralmente encontradas na boca $[80]$.

Os edulcorantes podem pertencer a diversas classes químicas devido a diversidade estrutural. Desta forma, muitos estudos têm sido realizados com o objetivo de conhecer a relação existente entre suas propriedades físicoquímicas e o sabor doce apresentado por essas substâncias [80].

Os edulcorantes utilizados neste trabalho foram a sucralose, aspartame, acessulfame-k, ciclamato e sacarina, os quais serão descritos a seguir.

\subsection{1- Sucralose}

A sucralose (1,6-dicloro-1,6-dideoxi- $\beta$-D-Frutofuranosil-4-Cloro-deoxi- $\alpha$ D-Galactopiranosídeo), é o único edulcorante de alta intensidade obtido através da sacarose, logo apresenta características sensoriais muito próximas à sacarose, possui um poder de doçura entre 400 e 750 vezes maior que a da sacarose dependendo do $\mathrm{pH}$, temperatura e produto aplicado [83]. 
A sucralose foi descoberta em 1976, na faculdade Rainha Elizabeth nos Estados Unidos. Estudos realizados mostraram que a sucralose não afeta niveis de glicose e insulina, pois não é reconhecido como carbohidrato pelo organismo, logo é considerado um adoçante ideal para os diabéticos. A Figura 5 mostra a estrutura química da sucralose.

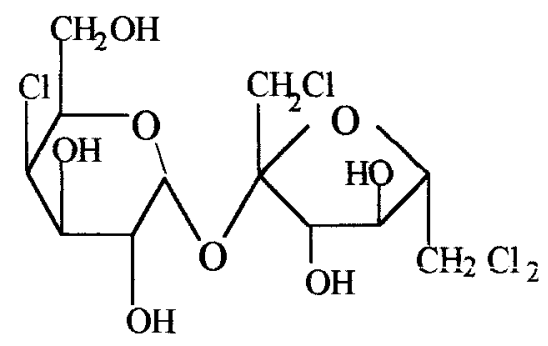

Figura 5- Estrutura química da sucralose [84].

A sucralose é um edulcorante aprovado pela Administração de Alimentos e Drogas (FDA), houve mais de 20 anos de estudos onde foram analisadas centenas de pesquisas sobre segurança e toxidade.

\subsection{2- Aspartame}

O aspartame é um éster metílico de dois aminoácidos, a fenilalanina e o ácido glutâmico. Sua estrutura é representada na Figura 6. Foi descoberto acidentalmente nos Estado Unidos em 1965, quando o J. M. Schaltter [80] desenvolvia um sedativo para úlcera. 
<smiles>COC(=O)C(Cc1ccccc1)NC(=O)C(N)CC(=O)O</smiles>

Figura 6- Estrutura química do aspartame [80].

Atualmente o aspartame é comercializado pelo nome NutraSweet, possui um poder de doçura entre 120 a 200 vezes maior que a sacarose. Esse poder de doçura varia com o sistema alimentar utilizado. Utilizando-se o aspartame em aromas de frutas ácidas, ocorre uma prolongação a percepção do sabor dessas frutas [84].

O aspartame apresenta uma baixa solubilidade em água (próximo de $1 \%$ a $25^{\circ} \mathrm{C}$ ), mas pode ser aumentada em função da diminuição do $\mathrm{pH}$ ou com o aumento da temperatura. Para um nível ótimo de diluição é recomendado uma temperatura de $40{ }^{\circ} \mathrm{C}$ e $\mathrm{pH} 4$ [84]. Através de estudos, o aspartame foi considerado um edulcorante seguro para pessoas normais, diabéticas e fenilcetonúricas heterozigotas (distúrbio congênito muito raro que aparece na infância e é caracterizado por sintomas nervoso, retardamento mental e lesões na pele, quando não tratados). Seu processo de aprovação teve início em 1973 e liberado pelo FDA em 1974 [84]. 


\subsection{3- Acesulfame-k}

O Acesulfame-k ou sal de potássio do 6-metil-1,2,3-oxatiazina-4(3H)-ona2,2-dióxido foi descoberto acidentalmente por pesquisadores alemães da Hoechst 1967 [80]. Inicialmente o ecesulfame-k era conhecido como "acetosulfam" e, em 1978 a Organização Mundial de Saúde registrou como o nome genérico "acesulfame potassium salt" e atualmente foi abreviado para acesulfame-k [84]. A Figura 7 mostra a estrutura química do acesulfame-k.

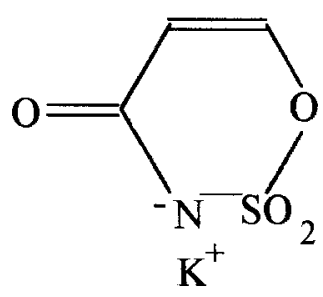

Figura 7- Estrutura química do acesulfame-k [84].

Em todos os paise onde o acesulfame-k é comercializado sua marca registrada é Sunnet ${ }^{\circledR}$ (Hoechst AG, Alemanha) exceto nos Estados Unidos onde a marca é conhecida como Sunntte ${ }^{\circledast}$ (Hoechst Celanese Corporation) [84].

O acesulfame-k é cerca de 180 a 200 vezes mais doce que uma solução de sacarose a 4 e $3 \%$, respectivamente. Não é higroscópico e rapidamente solúvel em água $\left(270 \mathrm{mg} / \mathrm{L}\right.$ a $20^{\circ} \mathrm{C} ; 1 \mathrm{Kg} / \mathrm{L}$ a $\left.100^{\circ} \mathrm{C}\right)$. Apresenta também um perfil de doçura semelhante ao da gluocose. 


\subsection{4- Ciclamato}

O cilcamato ou ácido ciclohexexilsulfâmico foi descoberto por Sveda, quando acidentalmente contaminou um cigarro com um derivado de ciclohexilamina. O ciclamato encontra-se em 4 formas químicas: ácido ciclâmico, ciclamato de cálcio, de sódio e de potássio. A Figura 8 mostra a estrutura química do ciclamato.

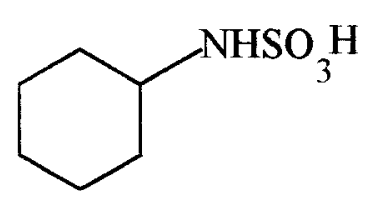

Figura 8- Estrutura química do ciclamato [84].

Os ciclamatos foram patenteados pela DuPont (laboratório Abbot) em 1940 e introduzidos no mercado em 1950. Devido ao prolongado sabor residual doce-azedo do ciclamato, não é possivel determinar exatamente seu poder de doçura em altas concentrações. Através da sua compatibilidade com outros aditivos como por exemplo, flavorizantes artificiais e naturais, o ciclamato é capaz de intensificar sabores naturais de frutas $[80,84]$.

\subsection{5- Sacarina}

A sacarina ou o-benzóide sulfimida, é um dos edulcorantes mais antigos. que se têm notícias. Foi descoberto acidentalmente e sintetizada por Falhberg em 1879 [80]. A Figura 9 mostra a estrutura química da sacarina. 


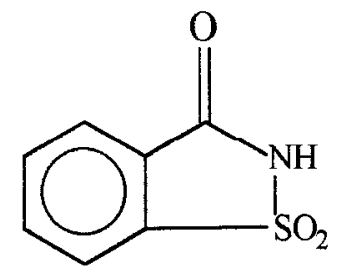

Figura 9- Estrutura química da sacarina [80].

Inicialmente, a sacarina foi utilizada como antisséptico e como conservante de alimentos. A partir de 1900 teve seu uso como edulcorante [84].

A sacarina apresenta um alto poder adoçante, cerca de 200 (em comparação com uma solução de sacarose a $10 \%$ ) a 700 vezes maior que a sacarose. 


\section{3- METODOLOGIA}

\section{1-Materiais}

\subsection{1- Polímeros e Dopantes}

A POEA, cuja estrutura química é apresentada na Figura 10, foi obtida por síntese química, utilizando-se o-etoxianilina (Aldrich Co.) como monômero. A síntese foi realizada de acordo com o método descrito por Mattoso e colaboradores [85] via reação de polimerização oxidativa em meio $\mathrm{HCl}$ $1,0 \mathrm{~mol} / \mathrm{L}$ utilizando persulfato de amônio como reagente oxidante, a $0^{\circ} \mathrm{C}$. A razão monômero oxidante foi de 4:1. O polímero foi obtido na forma de um pó escuro, após 2 horas de reação. Foi então filtrado em funil de Buchner com papel filtro Whatman $\mathrm{n}^{\circ} 4$ e lavado com $1,0 \mathrm{~L}$ de $\mathrm{HCl} 1,0 \mathrm{~mol} / \mathrm{L}$. Uma parte do polímero obtido foi lavado em solução de hidróxido de amônio 1,0 mol/L por 24 horas para a obtenção da POEA-EB. O polímero foi posteriormente seco em dessecador sob vácuo dinâmico por 24 horas. De acordo com a literatura a POEA obtida através dessa síntese apresenta uma massa molar entre 10.000 e $15.000 \mathrm{~g} / \mathrm{mol}$ e uma polidispersividade de $\left(M_{\mathrm{w}} / M_{n}\right)$ de 2,3 segundo a literatura [85].

A grande vantagem de se trabalhar com a POEA, que possui caracteristicas semelhantes às da PANI, é a sua solubilidade em vários tipos de solventes inclusive em água [86]. 


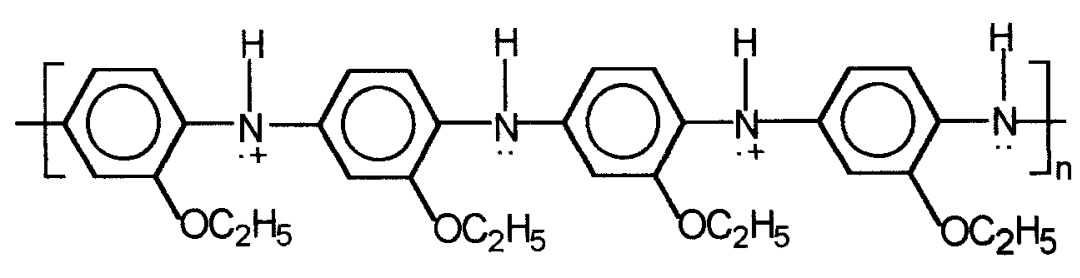

Figura 10- Estrutura química da POEA na forma dopada. Os contra íons foram omitidos.

Outro polímero utilizado para a fabricação dos filmes foi o poli(estireno sulfonato de sódio) (PSS) de massa molar de $70.000 \mathrm{~g} / \mathrm{mol}$ da Aldrich Co., cuja estrutura química é apresentada na Figura 11. Este polímero que se apresenta na forma de pó é totalmente solúvel em água.

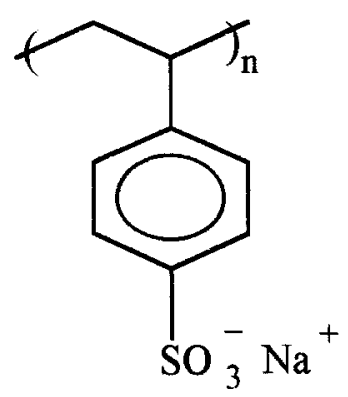

Figura 11- Estrutura química do poli(estirenosulfonato de sódio) (PSS).

Para o estudo de dopagens foram utilizados cloreto de sódio (Mallinckrodt Co.) (NaCl), dodecilbenzenosulfonato de sódio (DBSS$\mathrm{C}_{12} \mathrm{H}_{25} \mathrm{C}_{6} \mathrm{H}_{4} \mathrm{SO}_{3} \mathrm{Na}$ ) (Sigma Co.) e ácido dodecilbenzenosulfônico (ADBS$\mathrm{C}_{12} \mathrm{H}_{25} \mathrm{C}_{6} \mathrm{H}_{4} \mathrm{SO}_{3} \mathrm{H}$ ). A Figura 12 (a) e (b) mostra a estrutura química do DBSS e do ADBS respectivamente. O ADBS foi obtido a partir da troca catiônica do sal 
DBSS em coluna contendo resinas do tipo gel de polietilenos fortemente ácidos (Permutium Co.), onde o grupo trocador é o $\mathrm{SO}_{3}$ (sulfito), cuja forma iônica é a sódica. O objetivo desta troca catiônica é a substituição de todo sódio $\left(\mathrm{Na}^{+}\right)$do DBSS por hidrogênios $\left(\mathrm{H}^{+}\right)$.

Soluções dos diferentes dopantes foram preparadas em diferentes concentrações que serão citadas ao longo dos resultados e discussões.

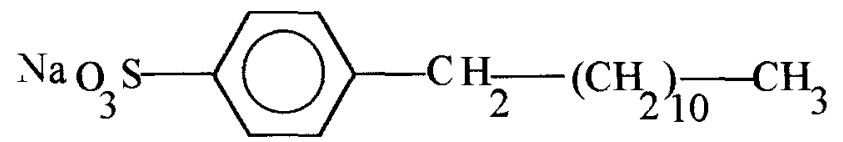

(a)

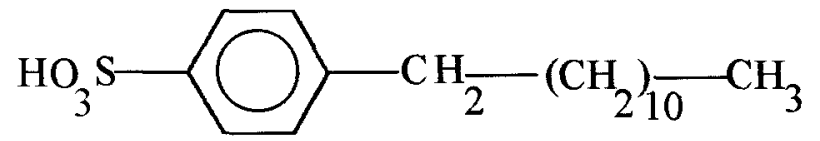

(b)

Figura 12- (a) estrutura química do DBSS; (b) estrutura molecular do ADBS.

3.1.2- Obtenção da poli(o-etoxianilina) dopada com ácido dodecil benzenosulfônico (POEA-ADBS)

Para este estudo utilizou-se $0,01 \mathrm{~g}$ de POEA EB dissolvido primeiramente em $20,0 \mathrm{~mL}$ de dimetilacetamida (VETC-99\%). Em seguida 
foram separadas quatro alíquotas de $5,0 \mathrm{~mL}$. Uma das alíquotas foi utilizado como branco. As outras três alíquotas foram acrescidas de 10, 30 e $40 \mu \mathrm{L}$ de ADBS respectivamente e mais $20,0 \mathrm{~mL}$ de água ultrapura.

O estudo de dopagem foi feita através de medidas de UV-VIS, onde verificou-se o aparecimento da banda polarônica por volta de $800 \mathrm{~nm}$, característico da POEA em seu estado dopado.

\subsection{3- Substrato}

Placas de vidro óptico (MM Optics) (dimensões 30X10X1 mm) foram utilizadas como substratos para a deposição dos filmes. Todas as placas foram lavadas conforme o método descrito por Kern [87], em que são primeiramente imersas em solução ácida de $\mathrm{H}_{2} \mathrm{SO}_{4} / \mathrm{H}_{2} \mathrm{O}_{2}, 7: 3(\mathrm{v} / \mathrm{v})$ a $80^{\circ} \mathrm{C}$ por 1 hora em ultrasom para a limpeza do substrato, seguido de extensiva lavagem com água ultrapura. Em seguida as placas são mantidas em solução básica de $\mathrm{H}_{2} \mathrm{O} / \mathrm{H}_{2} \mathrm{O}_{2} / \mathrm{NH}_{4} \mathrm{OH}$ 5:1:1 (v/v) por 40 minutos para a neutralização das cargas positivas provenientes da lavagem ácida em ultra-som e novamente lavadas com água ultrapura.

\subsection{4- Microeletrodos Interdigitados}

Um conjunto de filmes selecionados foi depositado sobre microeletrodos interdigitados contendo 50 pares de dígitos de ouro, fornecidos pelo Laboratório de Microeletrônica da Escola Politécnica da USP por intermédio do Prof. Dr. Fernando J. Fonseca. A Figura 13 mostra uma ilustração do microeletrodo 


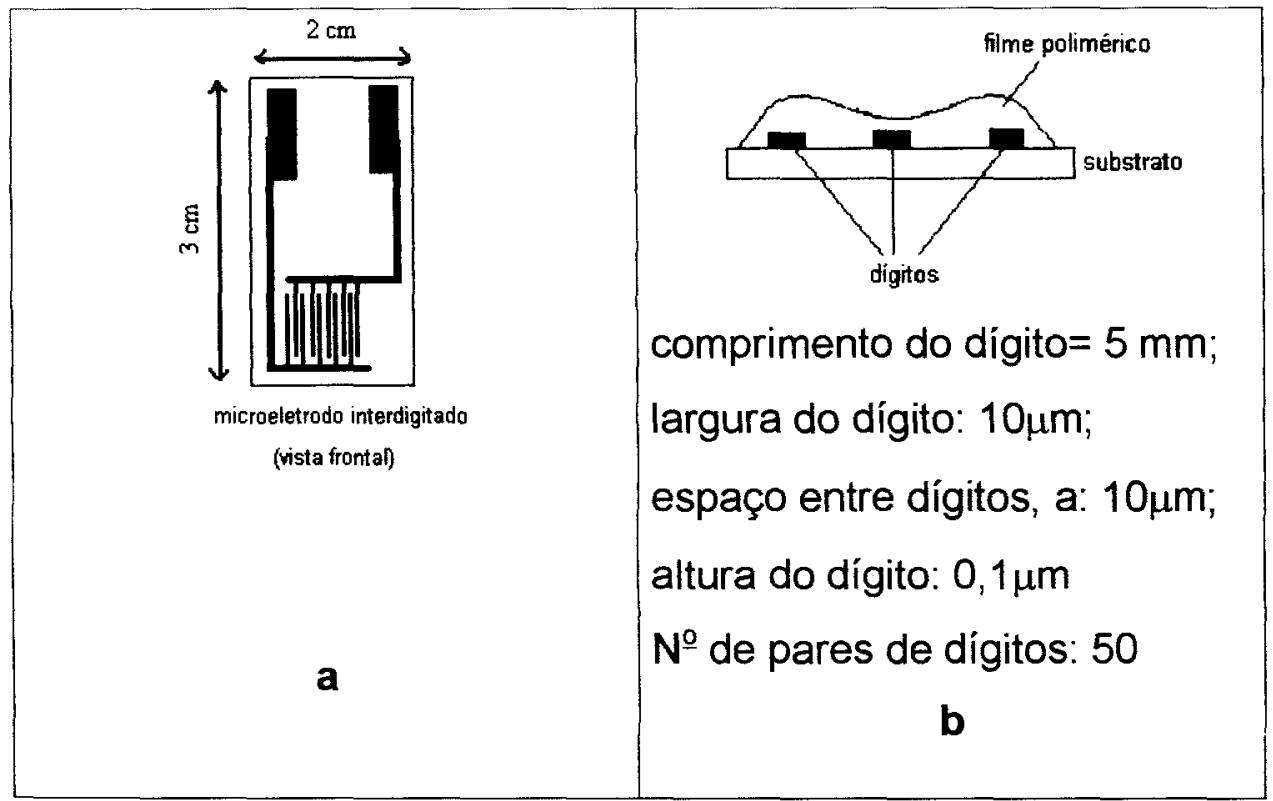

Figura 13- llustração simplificada de um microeletrodo interdigitado contendo 5 dígitos. a) Vista frontal; b) Vista lateral: microeletrodo recoberto com filme polimérico com descrição das dimensões.

\subsection{5- Soluções Utilizadas para as Medidas da Língua Eletrônica}

Foram utilizadas as seguintes soluções para as medidas elétricas:

- Sacarose (Mallinckrodt Co) $1 \mathrm{mM}$ (para paladar doce)

- Cloreto de sódio (Mallinckrodt Co) 1 mM (para paladar salgado)

- Ácido clorídrico (Chemco) $1 \mathrm{mM}$ (para paladar azedo)

Em seguida, foram realizadas medidas com edulcorantes

Os edulcorantes utilizados e suas concentrações estão na Tabela I. 
Tabela I- Edulcorantes, combinações de edulcorantes e sacarose com suas respectivas concentrações utilizadas para medidas com a Língua Eletrônica.

\begin{tabular}{cc}
\hline Substância & Concentração (g/100mL de água) \\
\hline Sacarose & 9,400 \\
Acesulfame-k & 0,080 \\
Aspartame & 0,063 \\
Ciclamato & 0,320 \\
Sacarina & 0,032 \\
Sucralose & 0,0143 \\
Sacarina + Ciclamato & 0,010 de Sacarina e 0,100 de Ciclamato \\
Acesulfame-k + Ciclamato & 0,0187 de Acesulfame-k e 0,0935 de Ciclamato \\
Acesulfame-k + Aspartame & 0,0215 de Acesulfame-k e 0,0215 de Aspartame \\
Sucralose + Ciclamato & 0,0077 de Sucralose e 0,1155 de Ciclamato \\
Sacarina + Ciclamato + Aspartame & 0,0067 de Sacarina, 0,067 de Ciclamato e 0,013 \\
& de Aspartame \\
\hline
\end{tabular}

Na Tabela II está apresentada os nomes dos fabricantes dos edulcorantes utilizados neste experimento.

Tabela II- Nome dos fabricantes dos edulcorantes e sacarose utilizada para as medidas com a língua eletrônica.

\begin{tabular}{|c|c|}
\hline $\begin{array}{l}\text { Produto } \\
\end{array}$ & Fabricante \\
\hline $\begin{array}{l}\text { Sacarose (nome comercial: } \\
\text { Açúcar Refinado especial }\end{array}$ & $\begin{array}{l}\text { COPERSUCAR - Cooperativa de Produtores de } \\
\text { Cana-de-açúcar, Açúcar e Álcool do Estado de São }\end{array}$ \\
\hline & \\
\hline Sacari & $\begin{array}{l}\text { Fab: Shanghai Fortune Chemical CO. Lt. } \\
\text { Exporter: Zhong Hua Fang. DA (H.K) Limited - } \\
\text { Brasfanta's Group }\end{array}$ \\
\hline Ciclamato de sódio & $\begin{array}{l}\text { Fab. e Exp: Zhong Hua Fang. DA (H.K) Limited - } \\
\text { Brasfanta's Group }\end{array}$ \\
\hline Acesulfame-k & $\begin{array}{l}\text { Manufacter: Vita Sweet CO. Lt. } \\
\text { Exporter: Zhong Hua Fang. DA (H.K) Limited - } \\
\text { Brasfanta's Group }\end{array}$ \\
\hline $\begin{array}{l}\text { Sucralose (Marca comercial } \\
\text { Splenda) }\end{array}$ & Fab: McNeil Specialty \\
\hline Aspartame & Fab: Cape Food Ingredients Brasil Ltda \\
\hline
\end{tabular}


O objetivo de se usar a combinação de edulcorantes é se conseguir um adoçante ideal não calórico. Um outro motivo de se fazer essas misturas é obter-se um adoçante com sabor similar ao da sacarose, mascarar o sabor residual, melhorar a estabilidade dos adoçantes, diminuir custos, reduzir a quantidade de adoçante utilizado fazendo com que a quantidade ingerida permaneça abaixo da ingestão diária aceitável (IDA), reduzir a contribuição calórica do adoçante e do produto final $[88,89]$. Ao combinar dois ou mais tipos de edulcorantes obtêm-se uma solução com alto poder adoçante devido ao sinergismo. O sabor doce obtido é importante mas deve-se levar em consideração que essas misturas devem apresentar também bom processamento, boa estabilidade e solubilidade [89, 90-93]

O sinergismo é mais pronunciado quando cada componente contribui com a mesma quantidade de doçura, ou seja, $50 \%$ da doçura final, correspondente à da sacarose $[89,94,95]$. Combinações de edulcorantes encontradas na literatura como os da Tabela 1, indicam uma proporção de 1:10 para sacarina + ciclamato, $1: 1$ acesulfame- $\mathrm{K}+$ aspartame, 1:4 acesulfame- $\mathrm{K}+$ ciclamato, 1:20 sucralose ciclamato e 1:5:8 sacarina + ciclamato + aspartame [89, 94]. Segundo Dyminski, as proporções encontradas em literaturas, nem sempre apresentam uma doçura semelhante a da sacarose, logo algumas combinações como o acesulfame-K + aspartame, sucralose + cilcamato e sacarina + ciclamato + aspartame foram desenvolvidas em seu laboratório através de testes com degustadores treinados para esse tipo de paladar, assim 
como o estudo das concentrações com edulcorantes isolados, para se chegar às concentrações com doçura semelhante ao da sacarose.

\section{2- Métodos}

\subsection{1- Fabricação dos Filmes por Automontagem}

Todos os filmes ultra-finos que foram estudados neste trabalho foram fabricados através da técnica de automontagem [96] conforme ilustrado na Figura 4 do item 2.5. Os filmes fabricados estão representados na Tabela III. A deposição dos filmes, foi realizada da seguinte forma: i) imersão do substrato na solução do policátion (POEA) por três minutos ii) lavagem do conjunto em água com o mesmo $\mathrm{pH}$ da solução do policátion e secagem do filme com gás nitrogênio; iii) imersão do conjunto já com uma camada do policátion na solução do poliânion (PSS) ou dos dopantes (ADBS, DBSS) pelo mesmo tempo. Repetiu-se os itens acima até a formação dos números de camadas desejadas.

Tabela III- Filmes fabricados por automontagem.

\begin{tabular}{cccc}
\hline Tipos de Filmes & Número de Camada & PH & Concentrações das Soluções \\
\hline POEA-EB & 10 & 5 & $1 \times 10^{-3} \mathrm{M}$ \\
POEA/ADBS & 10 & 5 & $1 \times 10^{-3} \mathrm{M} / 1 \times 10^{-3} \mathrm{M}$ \\
POEA/DBSS & 10 & 5 & $1 \times 10^{-3} \mathrm{M} / 1 \times 10^{-3} \mathrm{M}$ \\
POEA-HC//PSS & 10 & 5 & $1 \times 10^{-3} \mathrm{M} / 1 \times 10^{-3} \mathrm{M}$ \\
POEA + NaCI & 10 & 5 & $1 \times 10^{-3} \mathrm{M}+0,02 \mathrm{M}$ \\
POEA-ADBS & 10 & 3,25 & $1,85 \times 10^{-4} \mathrm{M}$ \\
POEA-ADBS/PSS & 10 & 3,25 & $1,85 \times 10^{-4} / 1,64 \times 10^{-4}$ \\
\hline
\end{tabular}




\subsection{2- Caracterização dos Filmes por Espectroscopia UV-VIS}

Os filmes fabricados neste trabalho foram caracterizados através de espectroscopia UV-VIS em um aparelho da marca Shimadzu modelo 1601PC, de duplo feixe, em um intervalo de comprimento de onda de 1100 a $190 \mathrm{~nm}$. Para tanto, espectros de UV-VIS foram obtidos após a deposição de cada camada polimérica depositada. Quando o pH das soluções foi variado, a quantidade de POEA adsorvida foi estimada em relação a um valor de absortividade obtido a partir de uma curva de calibração, considerando um $\lambda_{\text {máx }}=452 \mathrm{~nm}$. Este é o comprimento de onda que coincide com $\circ$ ponto isosbéstico encontrado nos espectros de soluções de POEA nos pH's 2, 3 e 5, como é mostrado na Figura 14. Neste valor de comprimento de onda não há variação da absorbância quando varia-se o pH.

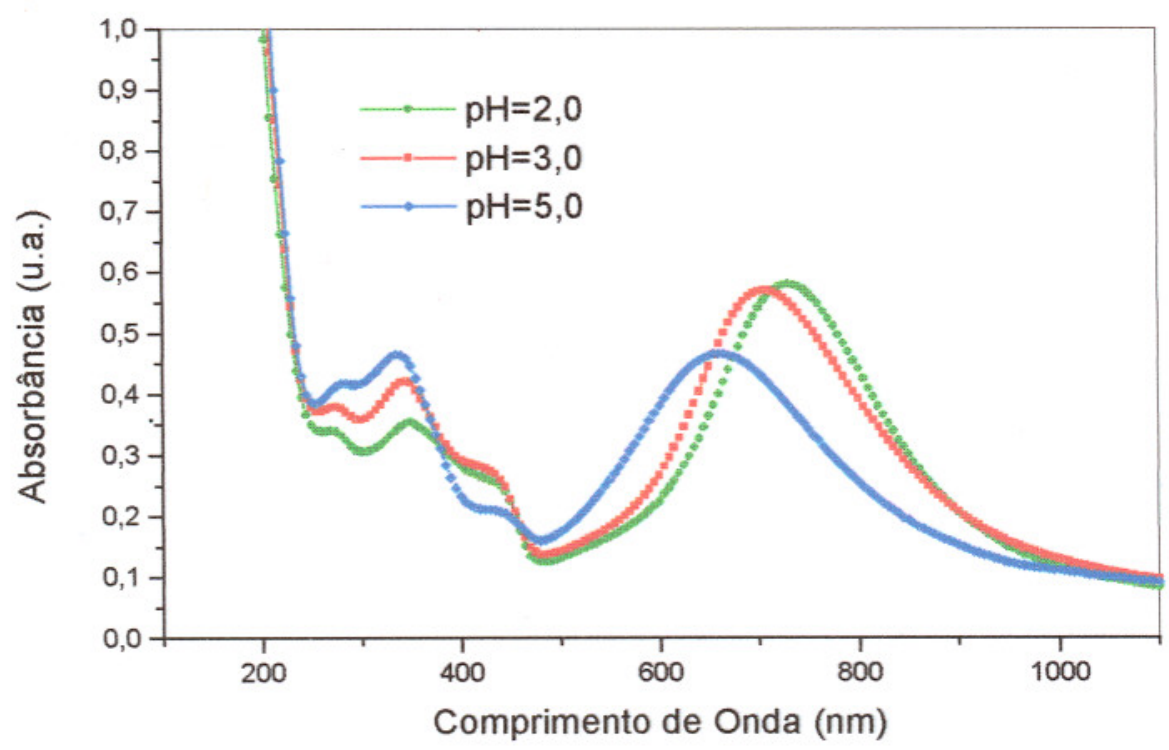

Figura 14- Espectro de UV-vis de soluções de POEA na concentração $0,04 \mathrm{~g} / \mathrm{L}$, dopadas comHCl em diferentes $\mathrm{pH}$ 's. 


\subsection{3- Microsocopia de Força Atômica-AFM}

A microscopia de força atômica-AFM (Atomic Force Microscopy) baseiase na obtenção de imagens da superfície da amostra, investigada pela sua interação com a ponta de uma agulha ou sonda (probe) onde são medidas as forças de interação entre os elementos em contato [97] (agulha e amostra). Neste trabalho procurou-se obter as imagens pelo modo de não-contato dos filmes fabricados, utilizou-se um microscópio de força atômica Topometrix, Discoverer, modelo TMX 2010, equipado com um "scanner" de $7 \times 7 \mu \mathrm{m}^{2}$ de área de varredura. Para o cálculo da rugosidade da superfície, foram utilizados softwares dedicados, como WSxM 4.0 develop 4.4, Nanotec Electronica S. L. (Copyright (C) November 2003) e Scanning Probe Image Processor (SPIP) Version 3.1.0.1 (Image Metrology AVS 2003).

O conjunto haste-agulha utilizado foi de nitreto de silicio (de formato em "V") para obtenção de imagens. As constantes elásticas, $k$, de silício e nitreto de silício são $(0,13 \pm 0,01) \mathrm{N} / \mathrm{m}$ e $(0,09 \pm 0,02) \mathrm{N} / \mathrm{m}$, respectivamente. As condições ambientais de análise variaram de $45 \%$ a $50 \%$ de umidade relativa do ar a temperatura de 24 a $26^{\circ} \mathrm{C}$.

O modo não contato baseia-se na separação da agulha em relação a amostra em torno de 10 a $100 \mathrm{~nm}$. Somente forças de interação de longo alcance, tais como eletrostáticas e forças de dipolo magnético irão interagir. 


\subsection{4- Filmes Utilizados para a Montagem da Língua Eletrônica}

Filmes de POEA foram depositados sobre os microeletrodos interdigitados por automontagem nas mesmas condições em que os filmes foram depositados em vidro. Um conjunto de quatro tipos de filmes depositados sobre microeletrodo interdigitados foram escolhidos para compor uma língua eletrônica, conforme mostrado na Tabela IV.

Tabela IV- Filmes utilizados para a fabricação da língua eletrônica.

\begin{tabular}{ccc}
\hline No do sensor & Filmes & $\begin{array}{c}\text { Concentração (mol/L) e pH dos } \\
\text { materiais }\end{array}$ \\
\hline 1 & Sem material & $1,85 \times 10^{-4}$ e pH3 3,8 \\
2 & POEA-ADBS/PSS & $1 \times 10^{-3} \mathrm{pH} 5$ \\
3 & POEA-HCl/PSS & {$[\mathrm{POEA}]=1 \times 10^{-3}$} \\
4 & POEA-HCl+ NaCl & $\mathrm{NaCl}]=0,02$ \\
& & $\mathrm{pH} 5$ \\
5 & POEA EB & $1 \times 10^{-3} \mathrm{pH} 4$ \\
\hline
\end{tabular}

\subsection{5- Medidas Elétricas do Sensor - Espectroscopia de Impedância}

Primeiramente foram realizadas medidas de capacitância de cada microeletrodo interdigitado antes e após a deposição dos filmes. Essas medidas foram realizadas em água destilada em um capacímetro da marca Agilent 4263 B LCR Meter. Essas medidas foram realizadas com o objetivo de se detectar prováveis curtos circuitos ou defeitos nos eletrodos.

As medidas nas soluções de sacarose, cloreto de sódio e ácido clorídrico foram realizadas em um medidor de impedância da marca Solartron-SI 1260 
interfaceado a um computador por meio de uma placa GPIB, que permite a obtenção de espectros em uma faixa de freqüência de $10 \mu \mathrm{Hz}$ a $32 \mathrm{MHz}$. O software utilizado para a interpretação das medidas foi desenvolvido pelo grupo de pesquisa do Laboratório de Eletrônica e Desenvolvimento da Embrapa Instrumentação Agropecuária. As medidas realizadas foram de capacitância elétrica. Todas as medidas foram realizadas a $25^{\circ} \mathrm{C}$ em banho termostático da marca Tecnal modelo TE 184.

Para cada solução de paladares, a Língua Eletrônica ficava em contato com a solução por cinco minutos antes de se iniciar as medidas. Após cada medida foi feito a lavagem da Língua Eletrônica por vinte minutos.

As medidas de edulcorantes e suas combinações foram realizadas da mesma forma citada acima. 


\section{4- Resultados e Discussões}

\section{1- Filmes de POEA}

Num primeiro estudo foi investigada a deposição de filmes contendo apenas camadas de POEA e filmes contendo camadas de POEA alternadas cọm diferentes substâncias a saber PSS, DBSS e ADBS (soluções aquosas). Para tanto, foram utilizadas soluções de POEA a $1 \times 10^{-3} \mathrm{~mol} / \mathrm{L}$ (aproximadamente $0,0611 \mathrm{~g}$ de POEA) em pH 5 (solução aquosa). O crescimento dos filmes foi acompanhado por medidas de UV-VIS. A Figura 15 mostra a evolução da absorbância em função do número de camadas de POEA depositadas.

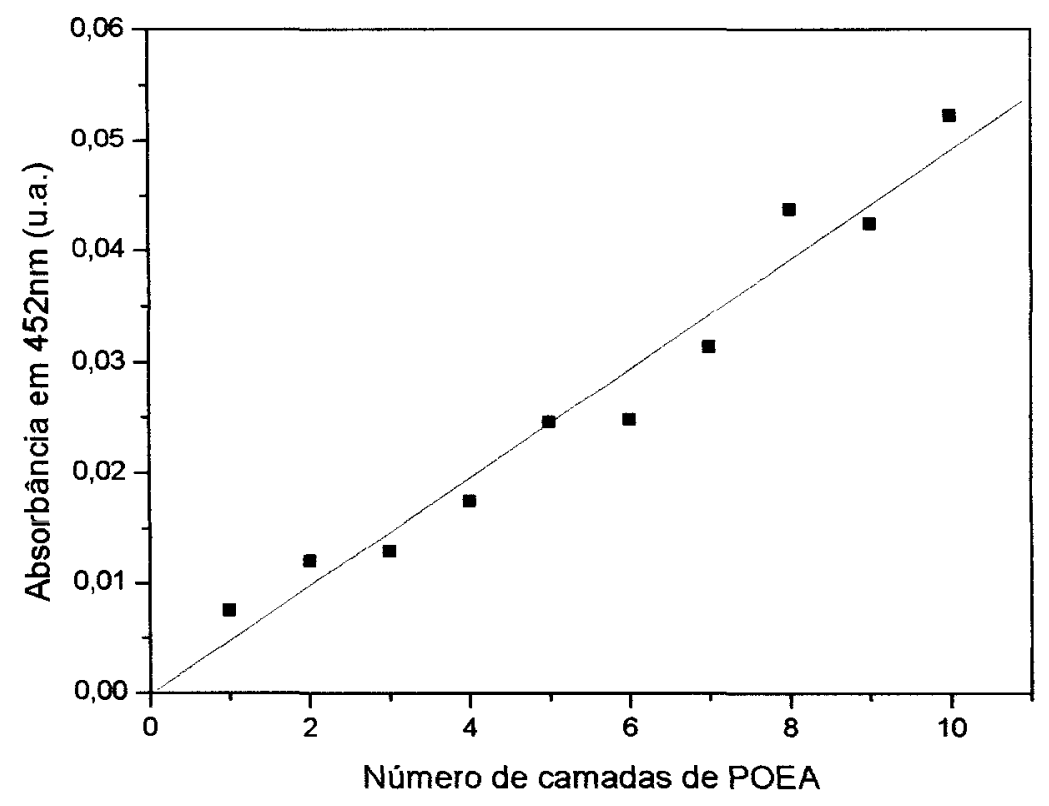

Figura 15- Variação da absorbância de um filme de POEA em função do número de camadas adsorvidas. Solução de POEA a $1 \times 10^{-3} \mathrm{M}$ em pH 5 . 
Como podemos observar, a absorbância aumenta aproximadamente linearmente com o número de camadas de POEA, o que significa que a cada camada depositada, uma mesma quantidade de POEA é adsorvida. De acordo com resultados obtidos no estudo de outros sistemas [66], o controle sobre a quantidade de polímero adsorvido tem sido conseguido quando combinações de policátions e poliânions são utilizadas. No entanto, no sistema em estudo temos apenas a presença de um único polímero o qual se apresenta na sua forma neutra, desprotonada [96] conforme o espectro de UV-VIS apresentado na Figura 16, indicado pela presença do pico máximo de absorbância em $616 \mathrm{~nm}$. Dessa forma não há a interação eletrostática e portanto o processo de adsorção deve se dar por outros tipos de interações. A PANI e seus derivados tendem a se agregar quando se encontram desprotonadas, decorrentes da formação de ligações de hidrogênio $[73,98]$, sugerindo que o mesmo pode estar ocorrendo em nosso sistema. 


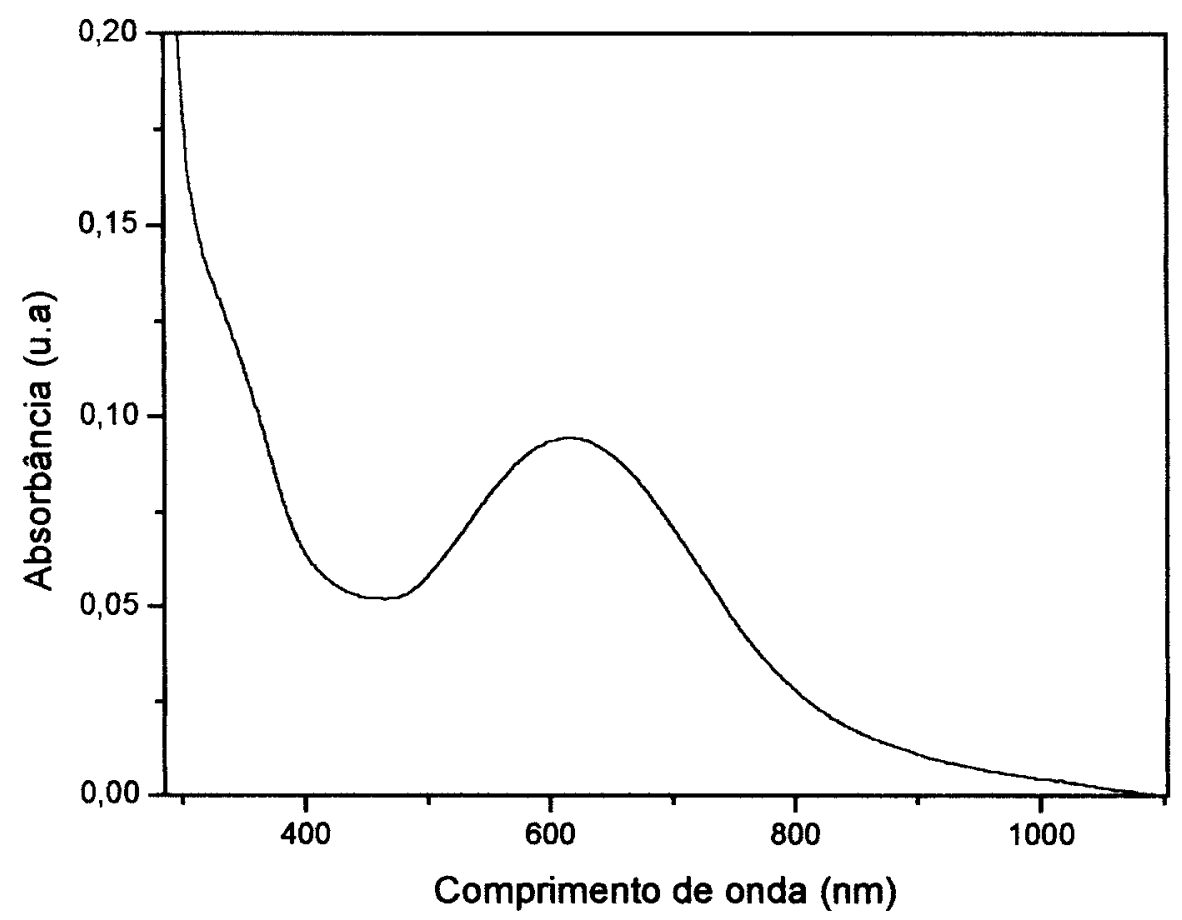

Figura 16- Espectro de UV-VIS da décima camada de POEA com concentração de $1 \times 10^{-3} \mathrm{M}$ e $\mathrm{pH} 5$.

Em um trabalho, realizado por Zheng e colaboradores [99], observou-se que a poli(o-metoxianilina) (POMA) em soluções de $\mathrm{pH}>4,5$ tende a se agregar, o que foi atribuído, com base em dados de espectroscopia de infravermelho e cromatografia de permeação em gel (GPC), a presença de ligações de hidrogênio. Ainda usando POMA, Raposo [100] e colaboradores observaram que a quantidade de polímero depositado aumenta com o pH como conseqüência da contribuição das ligações de hidrogênio. Estudos realizados por Paterno e colaboradores [101] com POEA, mostraram também que a quantidade de polímero depositado pode ser influenciado pelo valor do $\mathrm{pH}$ da solução polimérica. Utilizando-se soluções com pHs 2, 3 e 5, verificou-se que 
ocorre maior deposição do polímero em pH 5. Para pHs menores, como 2 e 3, a POEA encontra-se no estado dopado e consequentemente existem cargas na cadeia polimérica. Essas cargas provocam uma repulsão eletrostática entre as cadeias poliméricas, provocando dessa maneira uma menor adsorção de polímero sobre o substrato.

A Figura 17 ilustra a evolução da absorbância em função do número de bicamadas POEAIPSS adsorvidas. Novamente observa-se um crescimento linear da absorbância em função do número de bicamadas, indicando que uma mesma quantidade de POEA é adsorvida a cada camada depositada.

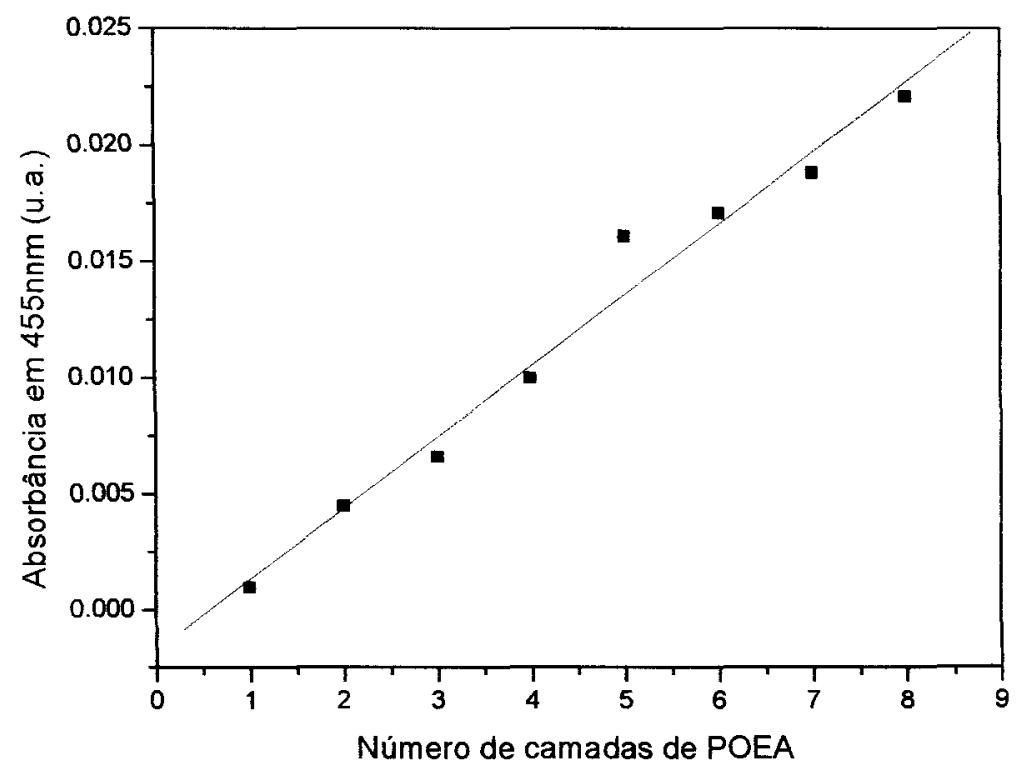

Figura 17- Variação da absorbância de um filme de POEA alternado com PSS em função do número de camadas adsorvidas. Solução de POEA e PSS a $1 \times 10^{-3} \mathrm{M} \mathrm{em} \mathrm{pH} 5$. 
Entretanto, foi observado que no filme de POEA/PSS a POEA se encontra protonada, uma vez que o espectro de UV-VIS deste filme mostra a presença da banda polarônica com máximo de absorbância em torno de 700nm, conforme apresentado a seguir na Figura 18.

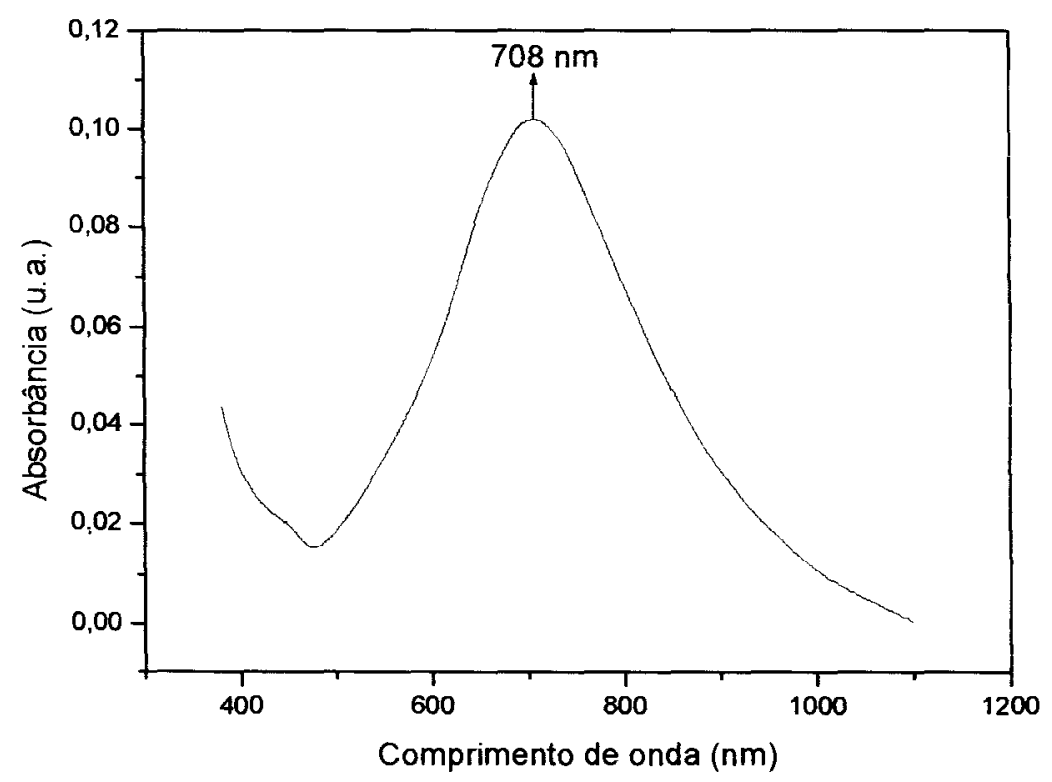

Figura 18- UV-VIS da décima bi camada POEA/PSS em pH 5 e com concentrações de $1 \times 10^{-3} \mathrm{M}$.

Em pH 5. a POEA deveria apresentar uma absorbância com comprimento de onda em torno de $600 \mathrm{~nm}$, típica de um polímero desprotonado, mas a presença do PSS provocou uma dopagem da POEA. Uma hipótese é que as cadeias de PSS blindam as poucas cargas presentes na POEA, induzindo a inserção de prótons da solução de deposição através de um deslocamento do equilíbrio de Donnan [102], já que a solução polimérica está em $\mathrm{pH}$ 5. Este resultado foi também observado com o sistema poli(o- 
metoxianilina)/poli(vinil sulfato de sódio) [103], o que corrobora nossas observações.

Num outro experimento filmes contendo camadas de POEA alternada com DBSS e ADBS foram fabricados e seu crescimento acompanhado por medidas de UV-VIS. A Figura 19 apresenta a evolução da absorbância de filmes de POEA/DBSS e POEA/ADBS.

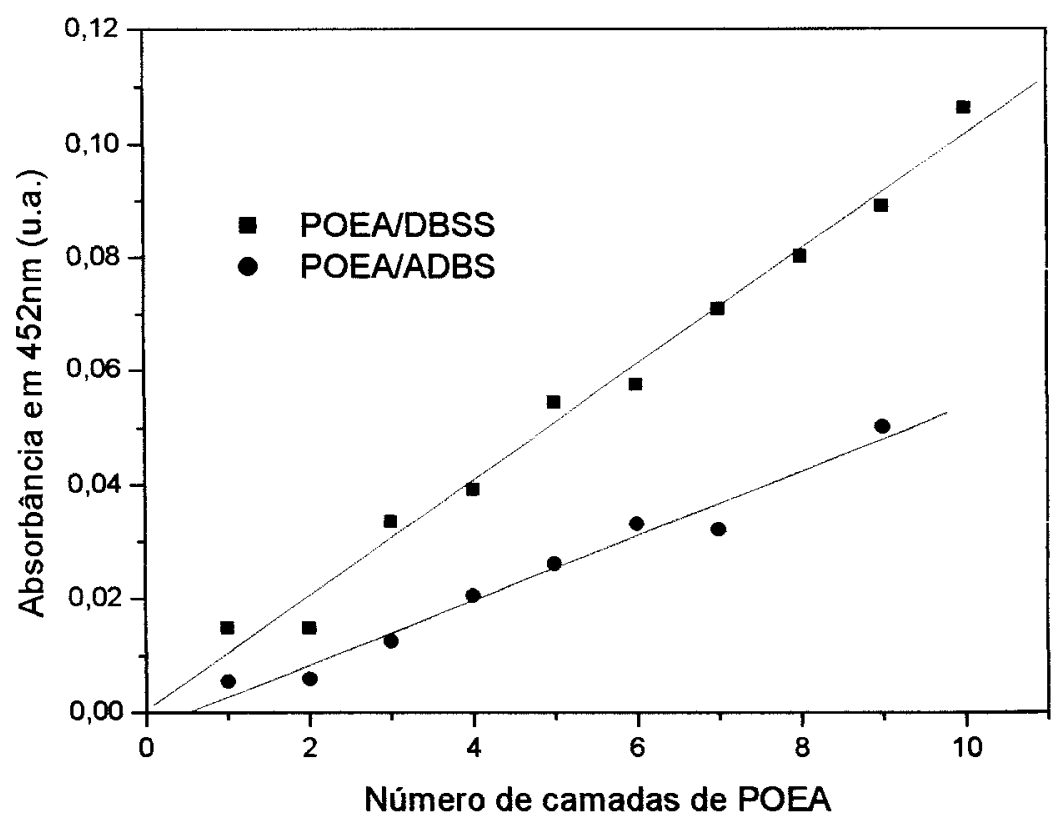

Figura 19- Variação da absorbância de filmes POEA alternado com DBSS e ADBS, todos em pH 5 e concentração de $1 \times 10^{-3} \mathrm{M}$.

Novamente observa-se um crescimento praticamente linear da absorbância em função do número de bicamadas, indicando que uma mesma quantidade de POEA é adsorvida a cada camada depositada, porém a absorbância do filme POEAJDBSS foi maior do que o filme de POEANADBS. 
Através dos espectros de UV-VIS, observou-se que, além de ocorrer a deposição de DBSS e ADBS sobre a POEA, ocorreu também a dopagem do filme de POEA. Este efeito é ilustrado na Figura 20.

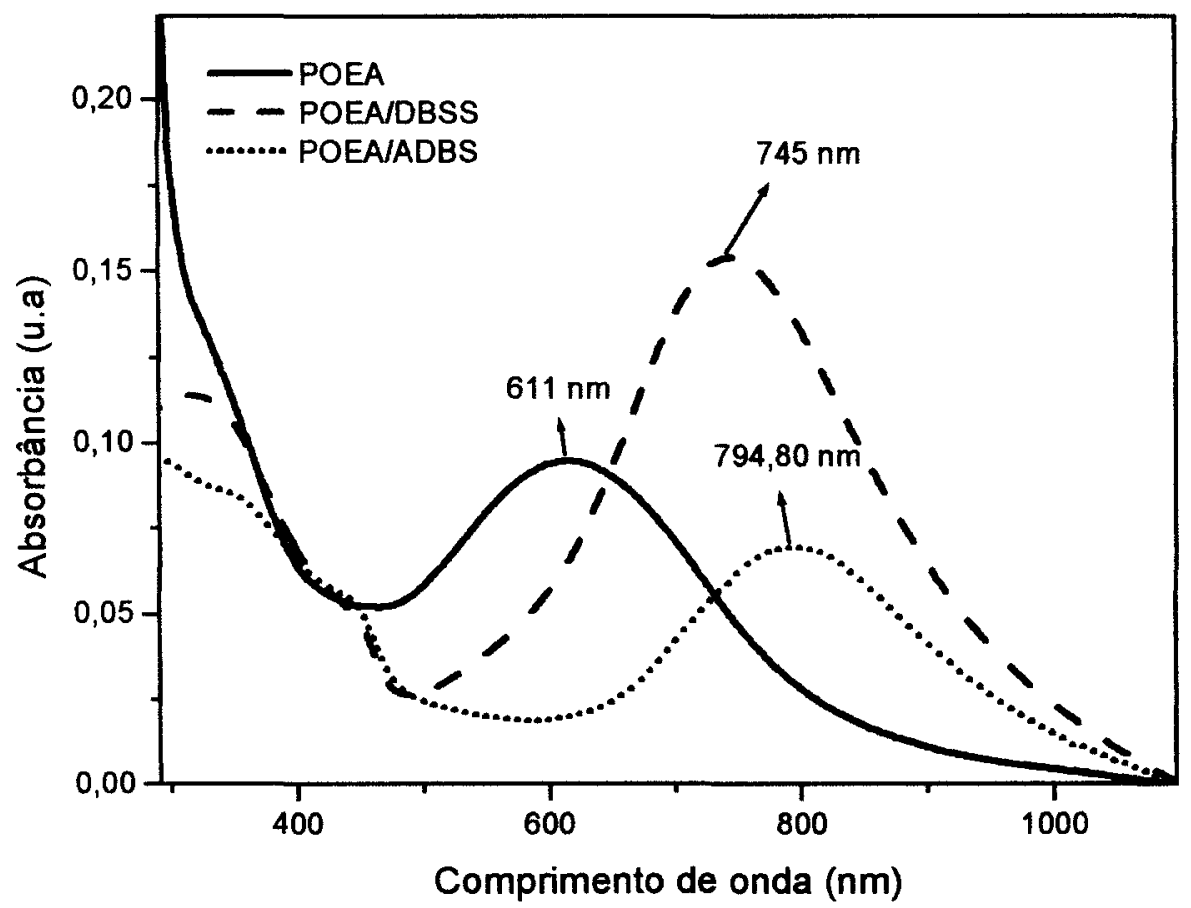

Figura 20- Espectros de UV-VIS da décima bicamada para comparação de dopagem e formação de filmes alternados de POEA com DBSS e ADBS em pH5 e concentração de $1 \times 10^{-3} \mathrm{M}$ para todas as soluções.

Como pode-se observar, o maior efeito de dopagem ocorreu utilizandose o ADBS como camada alternada. Observa-se também que a absorbância da POEAJDBSS é maior que a absorbância POEAJADBS. Segundo Kawagushi [104], quanto maior o poder de dopagem, menores são as chances de adsorção de material, devido a uma maior repulsão e conformação mais estendida das cadeias poliméricas, provocada pela maior quantidade de cargas no polímero. 
Já a utilização de DBSS, corrobora estudos realizados por Decher [105], que mostrou que a adição de sal às soluções poliméricas, provoca uma blindagem dos grupos iônicos das cadeias poliméricas, o que diminui a repulsão eletrostática intra e intermolecular, ocasionando um aumento da quantidade de material depositado. Obviamente o ADBS, como um ácido protônico, promove a dopagem da POEA via protonação. Por outro lado o DBSS induz a dopagem da POEA, através do deslocamento do equilíbrio de Donnan, conforme observado com o PSS.

Comparando-se os valores de absorbância entre POEAPSS e POEA/DBSS ambos em pH 5 e com 10 bicamadas ilustrados na Figura 21, observa-se os valores de absorbância de $\sim 0,10$ u.a. e $\sim 0,15$ u.a. respectivamente. 


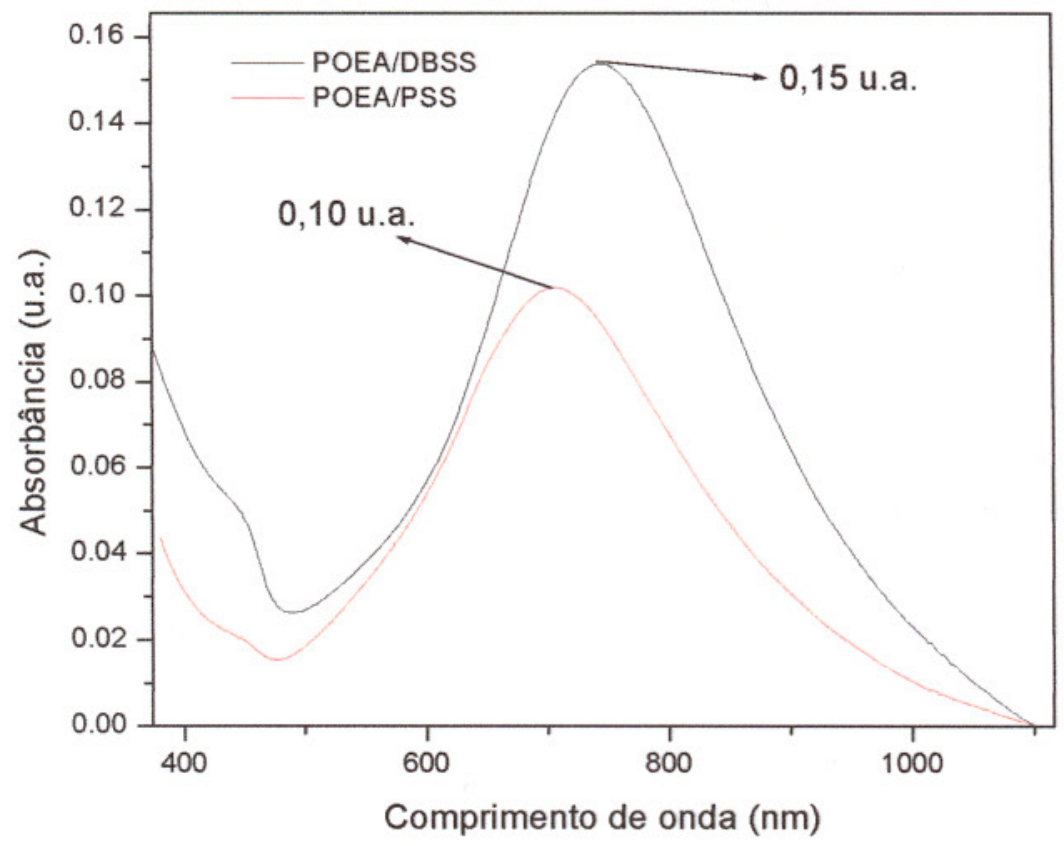

Figura 21- Espectros de UV-VIS da décima bicamada de POEA/DBSS e POEAIPSS.

Como pode-se observar a Figura 21, ocorre um maior depósito de material utilizando-se o DBSS. Apesar da diferença de absorbância ser pequena, este efeito pode ser explicado pela natureza de cada poliânion utilizado. O PSS por ser um polieletrólito, apresenta uma maior dificuldade de locomoção e acomodação sobre a POEA, enquanto que o DBSS por ser menor apresenta maior mobilidade, favorecendo uma blindagem mais eficiente da cadeia polimérica, ocasionando assim um maior depósito de material. 


\section{2- Obtenção de Filmes de POEA dopada com ADBS}

Nesta parte do trabalho, estudou-se a dopagem da solução de POEA EB utilizando-se DBSS e ADBS. Para tanto, uma solução aquosa de POEA-HCl foi desprotonada com solução de $\mathrm{NH}_{4} \mathrm{OH} 0,1 \mathrm{M}$ até atingir $\mathrm{pH} 5$ e posteriormente foi adicionado o dopante desejado. Da solução de POEA EB e dopante foi utilizado $1,0 \mathrm{~mL}$ de cada. Foi realizado também experimento em pH3 para verificar o efeito do dopante sobre a POEA em seu estado dopado. De todas as concentrações estudadas, resultados satisfatórios foram obtidos utilizando-se uma concentração de $5 \times 10^{-5} \mathrm{M}$ para a POEA e $1 \times 10^{-4} \mathrm{M}$ para as solução de DBSS e ADBS, pois nestas condições as soluções preparadas não apresentavam precipitação, visto que, este efeito ocorria em soluções de concentrações maiores.

A Figura 22 mostra os espectros de UV-VIS das soluções de POEA adicionadas de DBSS (solução aquosa). 


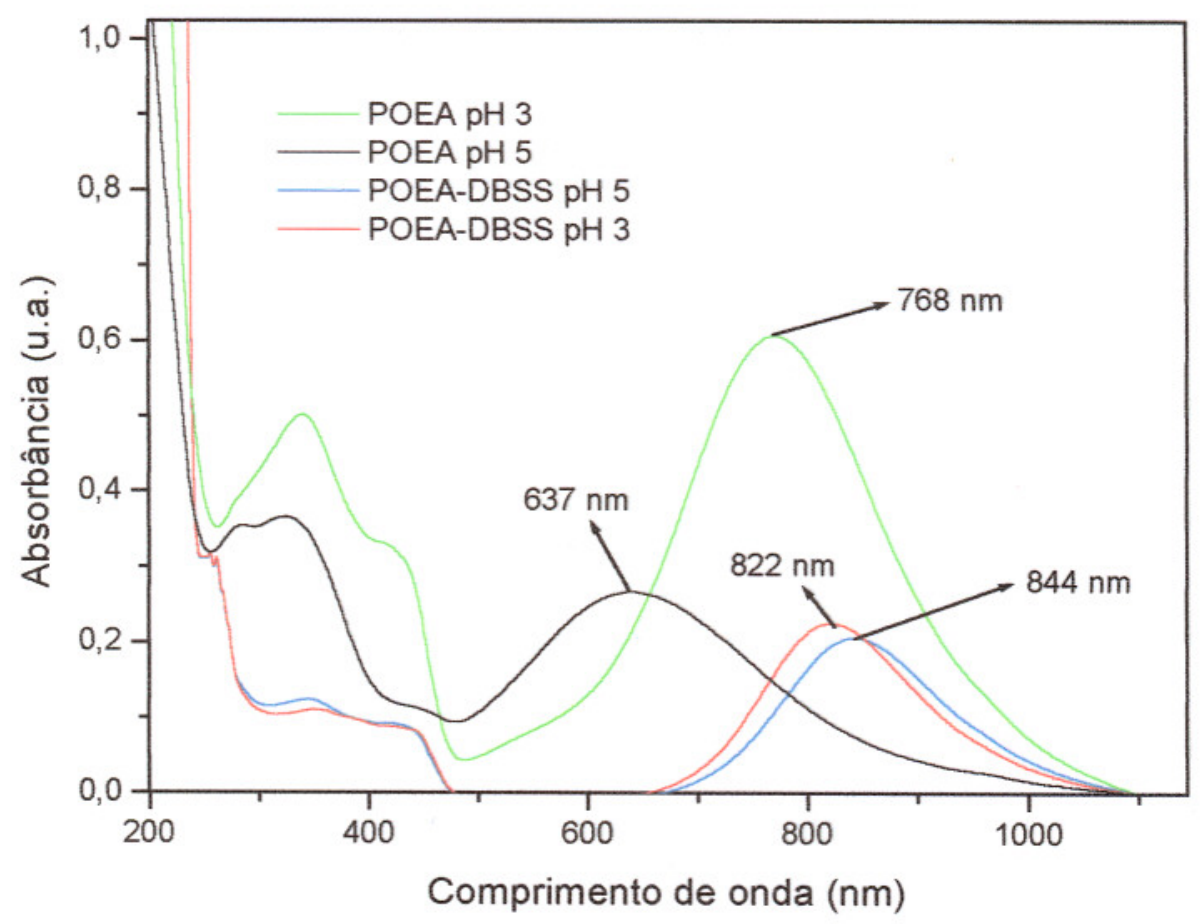

Figura 22- Espectros de UV-VIS para a formação de complexo e dopagem da POEA-DBSS (solução aquosa) em pH's 3 e 5 e concentrações de $5 \times 10^{-5} \mathrm{M}$ e $1 \times 10^{-4} \mathrm{M}$ para solução de POEA e DBSS respectivamente.

Conforme os espectros apresentados na Figura 22, observamos que a presença do DBSS ocasiona a dopagem da POEA em pH 5 haja visto que ocorre um deslocamento da banda de absorção de $637 \mathrm{~nm}$ da POEA pura em pH 5 para $822 \mathrm{~nm}$ para a POEA com DBSS. Este efeito foi menos intenso no caso da POEA em pH 3, já que o comprimento de onda da banda foi deslocada de $768 \mathrm{~nm}$ para $845 \mathrm{~nm}$, pois em pH 3 a POEA já está totalmente protonada e portanto o efeito do DBSS é menor. Por outro lado a POEA em pH 5 sofre a blindagem pelo DBSS e sua dopagem ocorre pelo deslocamento do equilíbrio de Donnan [102]. 
Utilizando-se o ADBS, os melhores resultados de dopagem foram utilizadas concentrações de $5 \times 10^{-5} \mathrm{M}$ e $1 \times 10^{-4} \mathrm{M}$ para a POEA e o ADBS (soluções aquosas) respectivamente. Essas concentrações forneceram soluções mais estáveis sem que ocorresse precipitação. Para estudar o efeito de $\mathrm{pH}$ 's foram utilizados os valores de 3 e 5 . Para este experimento também utilizou-se um volume de $1,0 \mathrm{~mL}$ para cada solução. A Figura 23 ilustra os espectros de UV-VIS obtidos.

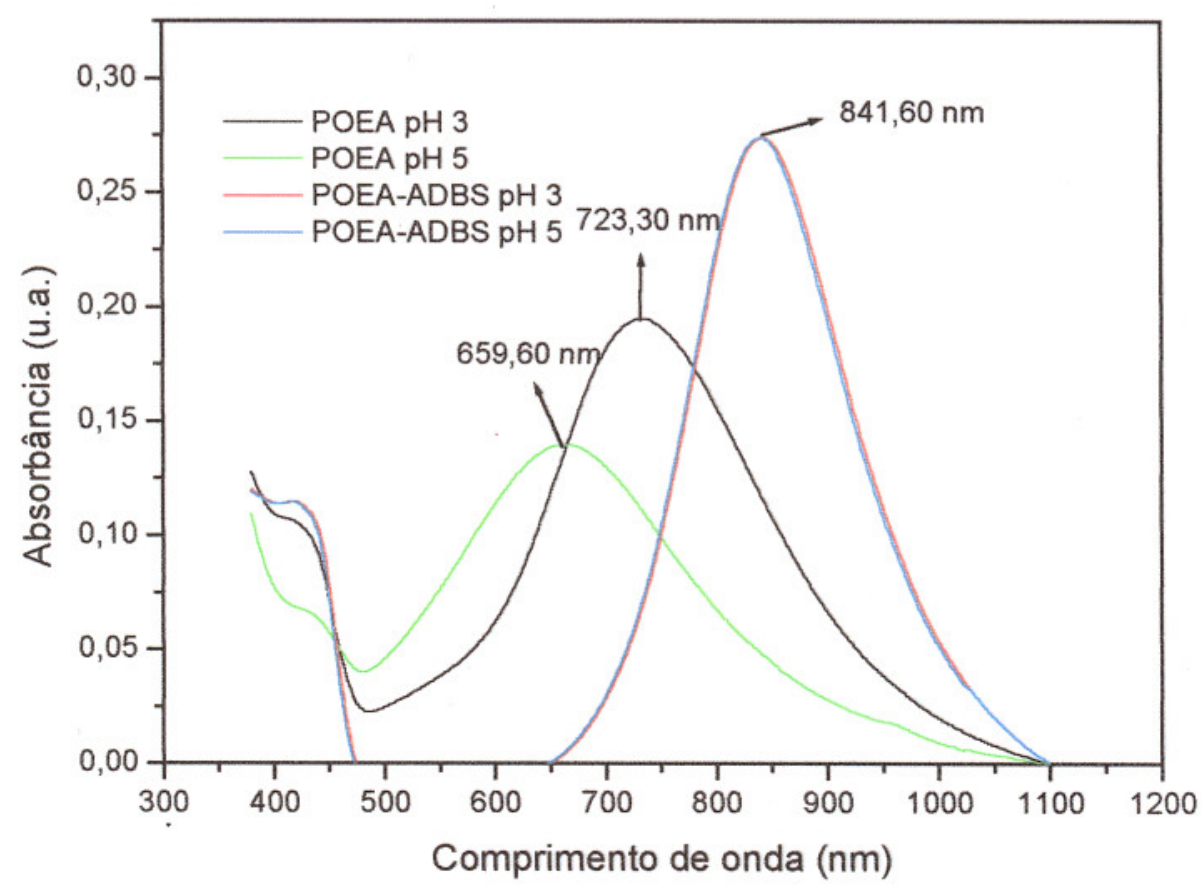

Figura 23- Gráfico de UV-VIS das soluções aquosas de POEA-ADBS e POEA com concentrações de $5 \times 10^{-5} \mathrm{M}$ e $1 \times 10^{-4} \mathrm{M}$ para a POEA e o ADBS respectivamente e $\mathrm{pH} 3$ e 5 . 
Como pode-se observar nos espectros da Figura 23 , houve a protonação da POEA como é visto pelo aparecimento da banda polarônica. Observa-se um mesmo comprimento de onda e absorbância tanto para o complexo em $\mathrm{pH} 3$ como para o pH 5, indicando que a formação deste complexo não depende do $\mathrm{pH}$.

Verificou-se com este estudo a possibilidade dos efeitos de dopagem serem ocasionados pela presença do íon sódio $\left(\mathrm{Na}^{+}\right)$, então, foram realizados experimentos com POEA (desprotonada com $\mathrm{NH}_{4} \mathrm{OH}$ ), adicionando-se $\mathrm{NaCl}$ para elucidar esta questão. A Figura 24 ilustra os espectros de UV-VIS que apresentaram maiores efeitos. Dentre as concentrações de $\mathrm{NaCl}$ estudadas $\left(1 \times 10^{-1}, 1 \times 10^{-2}, 1 \times 10^{-3}, 1 \times 10^{-4}\right.$ e $\left.1 \times 10^{-5} \mathrm{M}\right)$ a que provocou maior deslocamento da banda polarônica foi de $1 \times 10^{-1} \mathrm{M}$ em pHs 3 e 5 e para a POEA (solução aquosa) a concentração foi de $5 \times 10^{-4} \mathrm{M}$ em pHs 3 e 5 . Para o ajuste de $\mathrm{pH}$ foram utilizados $\mathrm{NH}_{4} \mathrm{OH} 0,1 \mathrm{M}$ e $\mathrm{HCl} 0,1 \mathrm{M}$. 


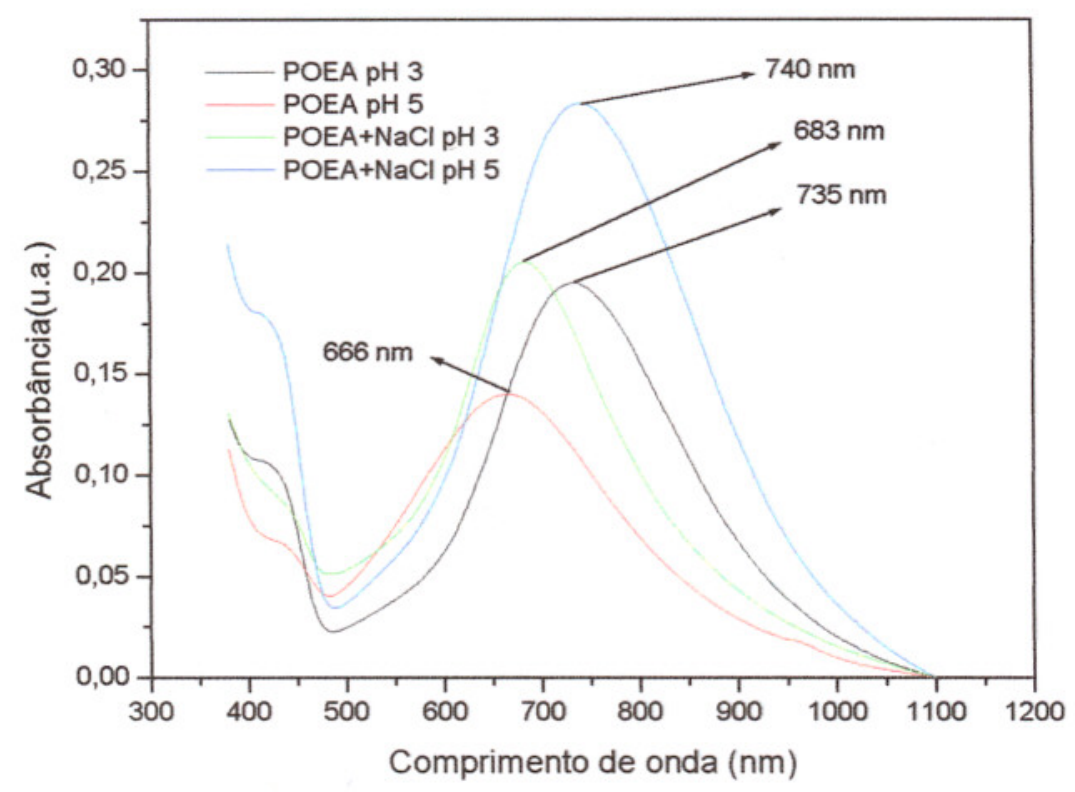

Figura 24- UV-VIS dos complexos (solução aquosa) POEA-NaCl em pH's 3 e 5. A concentração da POEA é $5 \times 10^{-5} \mathrm{M}$ e para o $\mathrm{NaCl} 1 \times 10^{-1} \mathrm{M}$.

Através dos valores de $\lambda$ obtidos para POEA-NaCl em pH $5(740 \mathrm{~nm})$ observados na Figura 24, observa-se que o efeito de dopagem é menor em relação ao estudo de POEA-DBSS (844 nm). Esta diferença mostra que, cada contra-íon colabora de uma maneira diferente para a dopagem da POEA. Devido ao contra-íon do DBSS apresentar caráter apolar e seu volume estérico maior que do $\mathrm{NaCl}$, este contribui para uma menor solvatação pela água, provocando assim um melhor efeito de blindagem, e logo uma maior dopagem pelo deslocamento do equilíbrio de Donnan. Já para as soluções de POEA$\mathrm{NaCl}$ em pH3, não observamos um deslocamento do equilíbrio de Donnan, visto que ocorre uma diminuição no $\lambda_{\text {máx. }}$ de $735 \mathrm{~nm}$ para $683 \mathrm{~nm}$ do espectro em relação a solução controle de POEA. Observa-se uma desprotonação desta 
solução, que deve ocorrer por diluição do sal com o ácido utilizado para o ajuste de $\mathrm{pH}$ no valor 3.

Após estes estudos tentou-se a deposição de filmes de POEA por automontagem, utilizando-se as soluções aquosas estudadas, pois segundo a literatura [106], surfactante como o DBSS e o ADBS possuem a capacidade de formação de filmes em soluções aquosas. No entanto, não foi possivel a formação de filmes de POEA-ADBS e POEA-DBSS, fato comprovado pelas análise de UV-VIS, provavelmente devido a baixa concentração das soluções. Conforme descrito anteriormente, para concentrações maiores a solução aquosa não era estável ocorrendo a precipitação da POEA. Assim, buscou-se um novo sistema solvente que permitisse obter uma solução estável para maiores concentrações. Segundo a literatura [107], a adição de dimetilacetamida permite a obtenção de soluções estáveis e deposição de filmes de PANI. Assim a nova solução de POEA EB é composta primeiramente por $0,01 \mathrm{~g}$ de POEA-EB dissolvido em $20,0 \mathrm{~mL}$ de solvente orgânico dimetilacetamida. Em seguida, foram separadas quatro alíquotas de $5,0 \mathrm{~mL}$. Três delas foram acrescentadas $0,02,0,03$ e $0,04 \mu \mathrm{L}$ de ADBS mais $20,0 \mathrm{~mL}$ de água ultrapura em cada alíquota, chegando-se assim em uma concentração de $1,85 \times 10^{-4} \mathrm{~mol} / \mathrm{L}$. Devido a um maior efeito de dopagem ocasionado pelo ADBS, este foi o dopante estudado para a dopagem da POEA EB. As três soluções apresentavam os respectivos pH's, 3,78; 3,56 e 3,25. Para a solução controle o $\mathrm{pH}$ aferido foi de 4.

A Figura 25 ilustra os espectros de UV-VIS obtidos das soluções. 


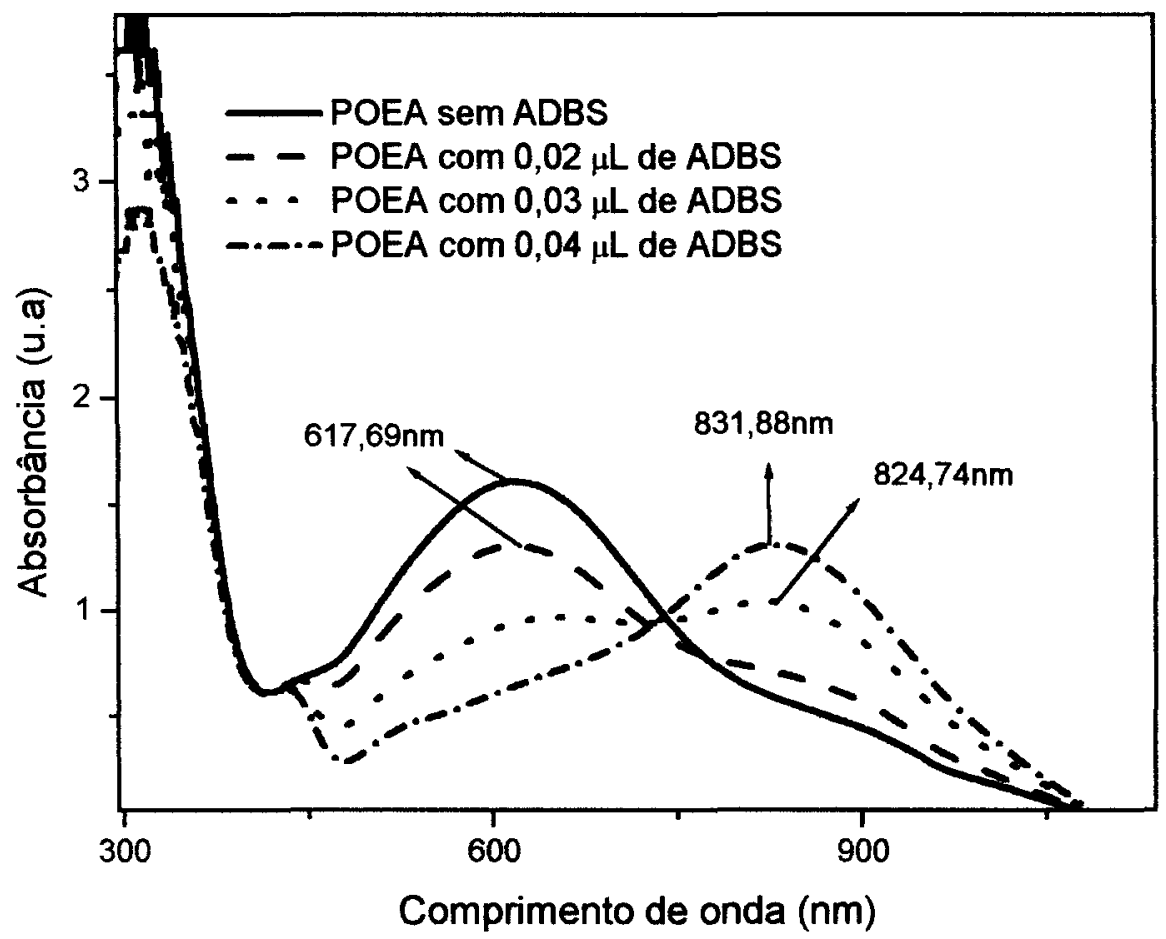

Figura 25- Espectros de UV-VIS para o estudo de dopagem da POEA EB com ADBS.

Como pode-se observar através da Figura 25, as condições utilizadas permitiram obter-se a POEA dopada com ADBS, em solução, no novo sistema de solvente, sendo que o maior valor da banda polarônica foi obtido para uma quantidade de $0,04 \mu \mathrm{L}$ de ADBS. Adição de uma quantidade maior que $0,04 \mu \mathrm{L}$ de ADBS, provocava precipitação da solução.

Estudos da literatura mostram que, para a PANI o uso de ácidos protônicos funcionalizados induz a formação de um complexo PANI com o contra ín do ácido, ao mesmo tempo que ocorre a dopagem [108]. Recentemente, pesquisas mostraram um processo térmico, onde a PANI EB 
quando misturada com o ADBS, produz a formação de um complexo condutor, a PANI-ADBS. O excesso de ADBS na mistura conduz a uma dispersão de partículas de PANI em ADBS. A pasta formada é ionicamente condutora. $\mathrm{O}$ aquecimento solidifica a pasta tornando-se assim, eletricamente condutor $(1-10 S / \mathrm{cm})$ [108]. Estudos realizados por Jana [109] et al., mostram comprimentos de onda de UV-VIS característicos de PANI dopado com ácido sulfônicos funcionalizados. Na Tabela $V$ são demonstrados estes valores. Os valores obtidos neste presente estudo estão de acordo com os valores abaixo, o que indica a dopagem da POEA pelo ADBS.

Tabela V- Valores característicos de comprimento de ondas para sistemas dopados com ácidos sulfonicos funcionalizados.

\begin{tabular}{cc}
\hline Comprimento de onda $(\mathbf{n m})$ & Transição \\
\hline$\sim 330$ & $\pi \rightarrow \pi^{*}$ \\
$\sim 440$ & Banda polarônica $\rightarrow \pi^{*}$ \\
$\sim 800$ & Banda polarônica \\
\hline
\end{tabular}

É importante ressaltar que a solução somente é estável quando o DMAC é adicionado antes do que a água, pois caso contrário ocorria precipitação da POEA . Uma possivel explicação pode ser devido a solvatação do dopante pelo DMAC. Esta solvatação promove uma proteção do dopante, fazendo com que após a adição da água não ocorra precipitação. 
Através dessa nova solução, foi feito o estudo de crescimento de filmes, que foram preparados com até dez camadas. A Figura 26 mostra a evolução da absorbância em função do número de camadas depositadas

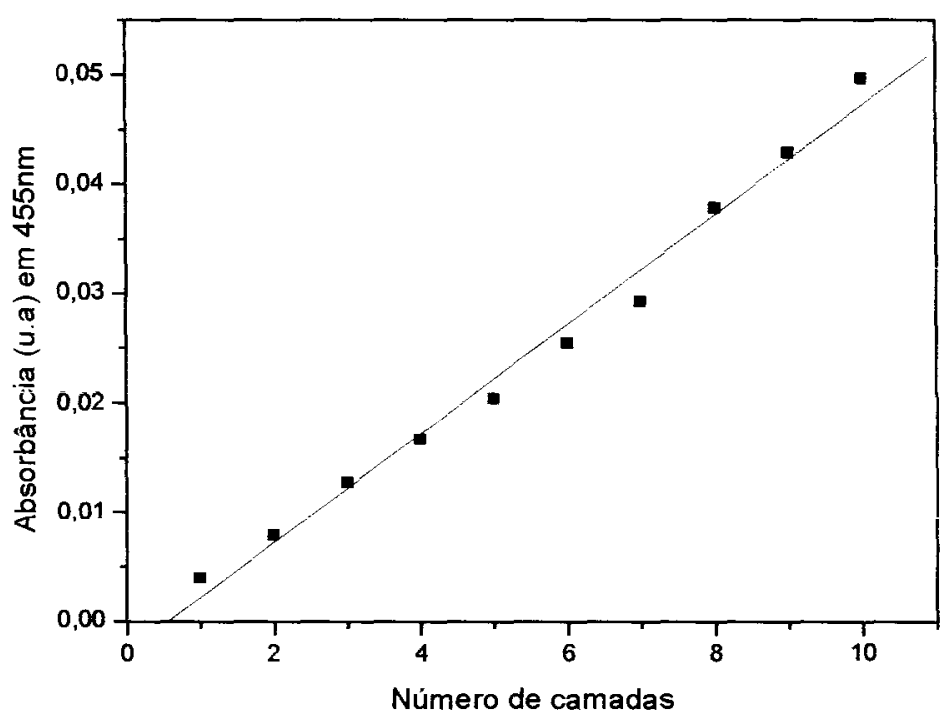

Figura 26- Evolução da absorbância em função do número de camadas de POEA dopada com ADBS com concentração de $1,85 \times 10^{-4} \mathrm{~mol} / \mathrm{L}$ e $\mathrm{pH}$ 3,25 (solvente DMAC $+\mathrm{H}_{2} \mathrm{O}$ ).

Como observa-se, a absorbância aumenta quase que linearmente com çada deposição de material, indicando assim, que há uma mesma contribuição de material a cada imersão realizada. Desta maneira, esta solução apresenta um potencial para a formação de filmes automontados utilizados em sensores como a língua eletrônica.

Finalizando este item, pode-se observar que a formação de filmes por automontagem, permite o controle de espessura dos filmes, visto que a cada 
deposição ocorre uma mesma contribuição de material depositado sobre o substrato. Observou-se também que a interação entre as camadas de POEA alternada com DBSS, ADBS ou PSS ocorre por pontes de hidrogênio quando em pH 5 e por atração eletrostática quando em pH 3 e que pode-se obter filmes de POEA dopado quando alternado com DBSS, ADBS ou PSS além de se ter conseguido uma solução de POEA dopada com ADBS.

\section{3- Estudo da Morfologia dos Filmes por Microscopia de Força}

\section{Atômica (AFM)}

Neste capitulo serão apresentados os resultados referentes ao estudo da morfologia de filmes automontados de POEA crescidos a partir das soluções de DMAC $+\mathrm{H}_{2} \mathrm{O}$ por microscopia de força atômica. Este estudo teve como objetivo avaliar a influência do dopante na formação das camadas e bicamadas, já que imagens obtidas por AFM possibilitam um estudo detalhado de rugosidade da amostra e quantificação do tamanho de grãos devido a sua boa resolução vertical. Todas as imagens apresentadas neste capitulo são representativas das três regiões diferentes de cada amostra analisada.

A Figura 27 mostra as imagens 3D de cinco camadas de POEA- ADBS e 5 bicamadas de POEA-ADBS/PSS e o perfil topográfico dos respectivos filmes. Todas as soluções utilizadas para a formação dos filmes apresentavam concentração de $1,85 \times 10^{-4} \mathrm{~mol} / \mathrm{L}$ e pH 3,25. 


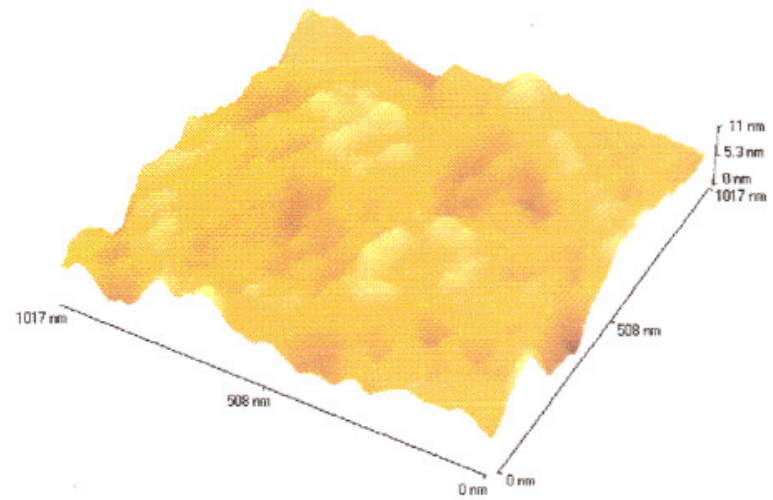

(a)

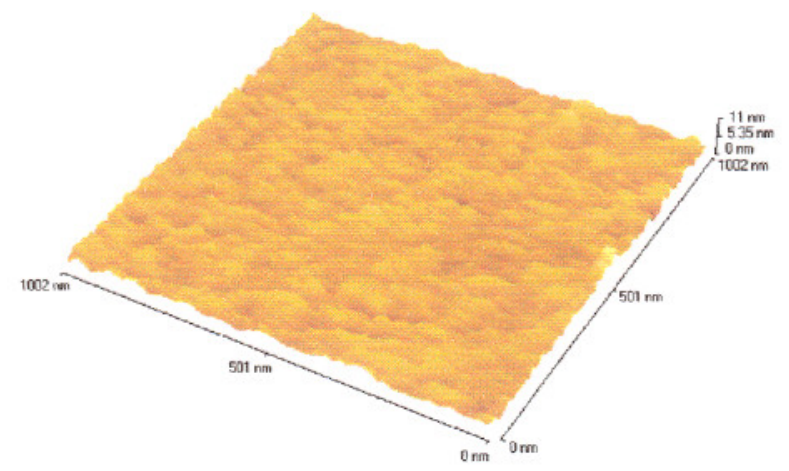

(b)

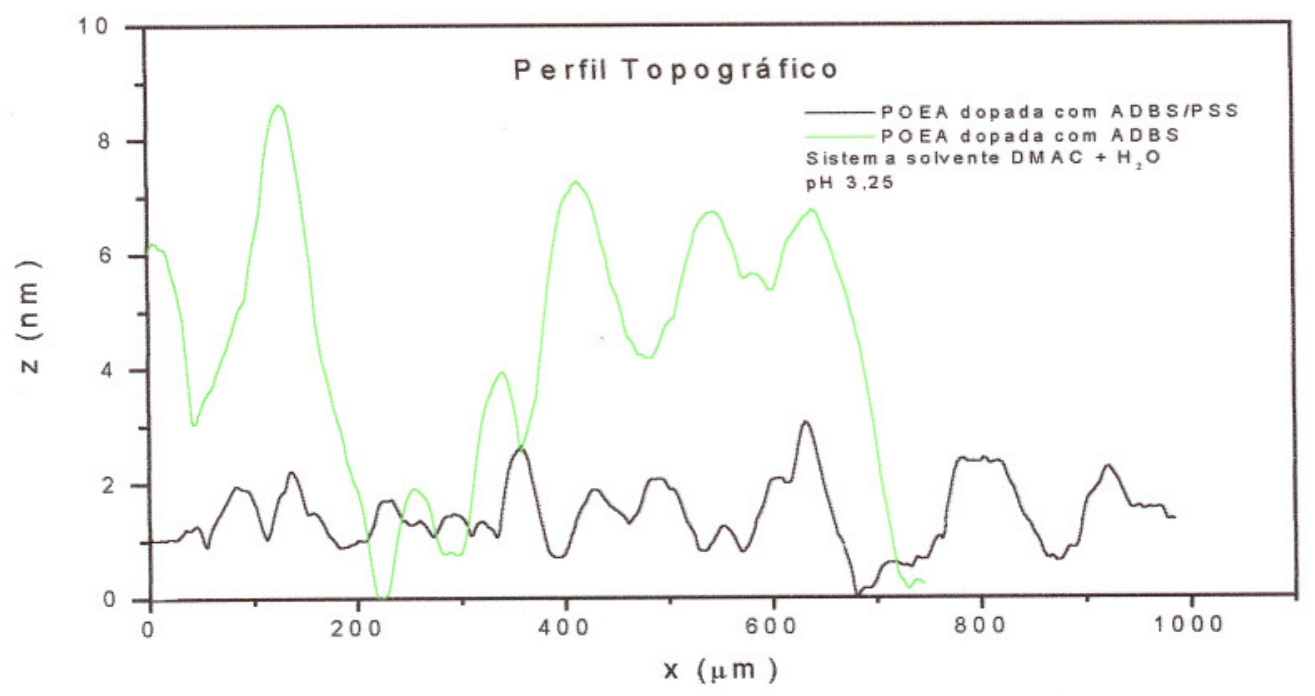

(c)

Figura 27- (a) imagem 3D de filmes contendo 5 camadas de POEAADBS em $\mathrm{pH} 3,25$ e (b) imagem de 5 bicamadas de POEA-ADBS/PSS em pH 3,25 (solvente DMAC $+\mathrm{H}_{2} \mathrm{O}$ ) (c) Perfil topográfico dos filmes estudados. 
Como pode se observar, os filmes apresentam morfologias diferentes. 0 filme contendo apenas camadas de POEA apresenta glóbulos, enquanto que o filme de POEA alternada com PSS exibe uma superfície mais plana, embora possam ser identificados pequenos glóbulos. Resultado referentes a imagem de POEA-ADBS apresenta semelhança em estudos de filmes automontados de POMA e de POEA dopados com $\mathrm{HCl}[55,100,101]$ e a presença de glóbulos tem sido atribuída a um mecanismo de adsorção que compreende duas etapas: nucleação e crescimento. Na primeira etapa, as primeiras cadeias poliméricas adsorvidas formam pequenos núcleos que servem de base para adsorção de mais polímero. Com a evolução da adsorção, os sítios presentes no substrato são ocupados rapidamente por cadeias poliméricas que formam os núcleos. Posteriormente, esses núcleos incorporam mais polímero e tendem a crescer radialmente até que encontrem um glóbulo vizinho, ocorrendo então a coalescência $[55,100,101]$. Fica evidente que a adsorção de camadas de PSS modifica a superfície dos filmes tornando-a mais lisa. Essa conclusão fica evidenciada pelos valores de rugosidade medidos para os dois filmes, sendo: 2,1 nm para o filme contendo apenas POEA e de $1,0 \mathrm{~nm}$ para o filme contendo camadas alternadas de POEA e PSS.

A adsorção de camadas subseqüentes de um mesmo policátion, no caso a POEA, é reduzida uma vez que a mesma repulsão eletrostática diminui a quantidade de material adsorvido e logo, os possíveis defeitos decorrentes da deposição são minimizados e a rugosidade não aumenta significativamente. Entretanto, quando camadas de PSS são adsorvidas, os espaços entre os 
glóbulos podem ser preenchidos com cadeias de PSS, as quais são relativamente flexíveis devido a uma estrutura hidrocarbônica simples. Este efeito já foi observado em outros sistemas, como no caso de filmes de proteínas globulares com PSS, cuja rugosidade é sempre menor na camada de PSS em relação a camada de proteína, como também no caso de filmes de POEA alternada com lignina-sulfonada [101], onde a rugosidade medida foi sempre menor na camada de LS em relação a camada de POEA.

\section{4- Medidas Elétricas}

Afim de se verificar o potencial dos filmes estudados para a montagem de uma língua eletrônica, foram realizadas medidas de capacitância em água destilada com os eletrodos interdigitados sem a deposição de filmes, afim de se verificar possíveis curtos circuitos que poderiam prejudicar medidas futuras. Mediu-se também a capacitânica em água destilada após a deposição dos filmes afim de verificar as mudanças de valores nas medidas ocasionados pela deposição dos filmes poliméricos. Foram utilizadas medidas de capacitância, pois alguns pesquisadores identificaram que é possivel aumentar de maneira significativa a sensibilidade de sensores de gás através de medidas AC [101]. Outra vantagem também apresentada é que essas medidas evitam o deslocamento de espécies químicas ionizadas no interior do filme polimérico, o que pode alterar irreversivelmente suas propriedades elétricas, sendo portanto um processo de análise repetitivo e não destrutivo. 
Foram utilizados cinco microeletrodos de ouro interdigitados, sendo um sem filme.

Para a fabricação do sensor, foram utilizados os seguintes filmes:

- $\quad$ Sem filme (eletrodo 1)

- $\quad$ POEA-ADBS/PSS (DMAC $+\mathrm{H}_{2} \mathrm{O}$ ): 5 bicamadas (eletrodo2)

- $\quad$ POEA-HCI/PSS $\left(\mathrm{H}_{2} \mathrm{O}\right): 5$ bicamadas (eletrodo 3 )

- $\quad$ POEA+NaCl $\left(\mathrm{H}_{2} \mathrm{O}\right): 5$ camadas (eletrodo 4)

- $\quad \operatorname{POEA}(E B)\left(\mathrm{H}_{2} \mathrm{O}\right): 5$ camadas (eletrodo 5)

A Tabela VI demonstra os resultados de capacitâncias dos quatro eletrodos antes e após a deposição dos filmes, na freqüência de $1 \mathrm{KHz}$, medidos em água destilada. Com estes valores obtidos, verificou-se que não havia defeitos nos eletrodos interdigitados.

Tabela VI- Valores de capacitância em $1 \mathrm{KHz}$ para os eletrodos antes e após deposição de filmes poliméricos.

Filmes
Capacitância antes do

filme $(F)$

$1,79 \mathrm{E}-08$

9,01E-09

1,94E-08

$1,94 \mathrm{E}-08$
Capacitância depois do filme $(F)$

\begin{tabular}{ccc}
\hline POEA-ADBS /PSS (E2) & $1,79 E-08$ & $9,40 \mathrm{E}-09$ \\
POEA-EB /PSS (E3) & $9,01 \mathrm{E}-09$ & $1,29 \mathrm{E}-08$ \\
POEA-EB+ NaCl (E4) & $1,94 \mathrm{E}-08$ & $7,61 \mathrm{E}-09$ \\
POEA-EB (E5) & $1,94 \mathrm{E}-08$ & $4,88 \mathrm{E}-09$ \\
\hline
\end{tabular}


Através dos valores da tabela VI pode-se observar que a realmente há uma influência dos filmes depositados sobre os eletrodos.

Para o teste de sensibilidade e de identificação de paladares da Língua Eletrônica foram realizadas medidas de capacitância em soluções que imitam os paladares básicos sentidos pela língua humana com soluções de cloreto de sódio para paladar salgado, ácido clorídrico para o paladar azedo, sacarose para o paladar doce e com água destilada, durante três dias consecutivos. Todas as soluções de paladares apresentavam uma concentração de $1 \times 10^{-3} \mathrm{M}$.

A Figura 28 ilustra o gráfico de capacitância versus unidade sensorial em freqüência de $1 \mathrm{KHz}$ para água destilada e paladares azedo, doce e salgado.

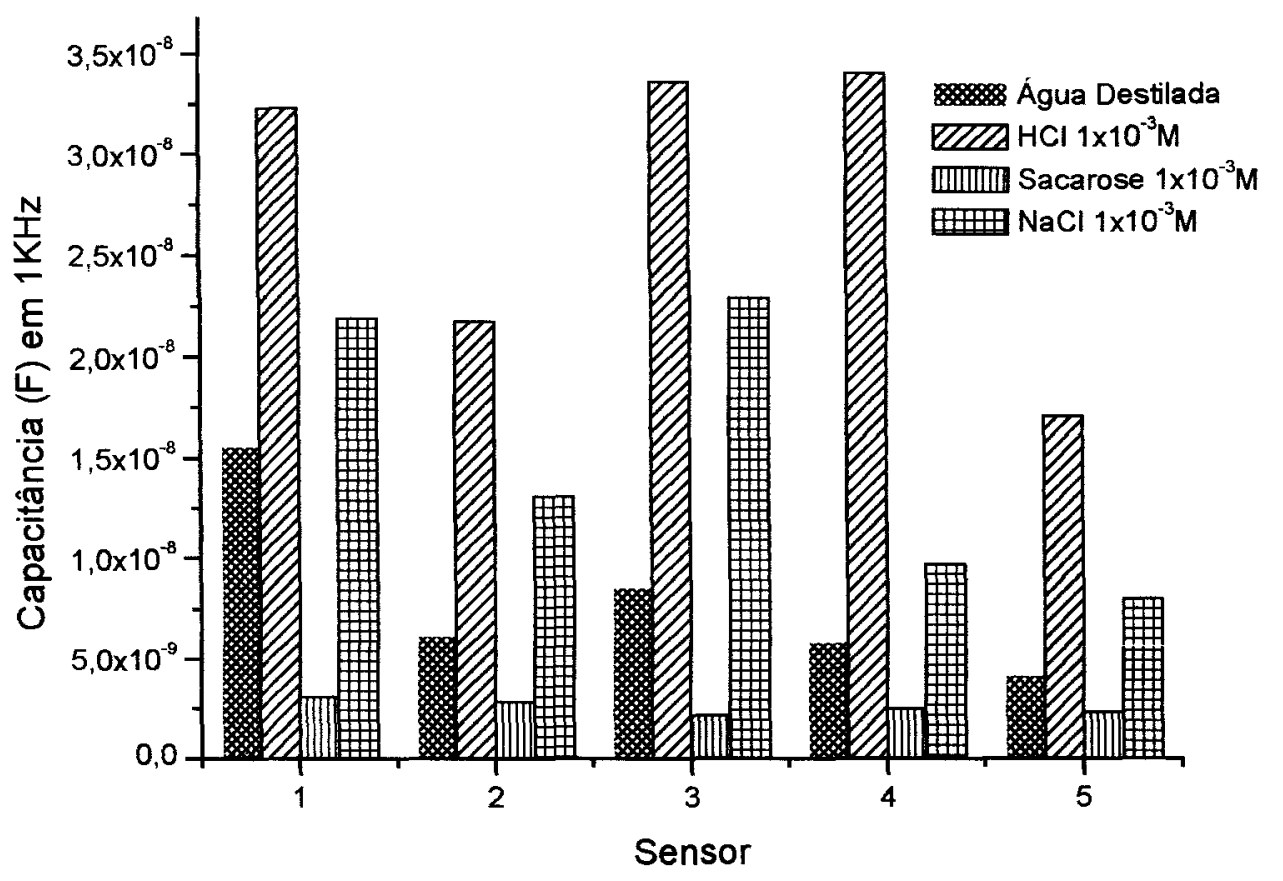

Figura 28- Gráfico de respostas de medidas de capâcitancia para cada tịpo de paladar e água destilada. 
Através dos valores obtidos, observa-se que para substâncias que formam íons em solução e para água destilada têm-se valores altos de capacitância em relação a sacarose. Esta por não formar íons quando em solução forneceu valores satisfatórios.

Para as medidas dos paladares foi necessário escolher uma freqüência ideal de trabalho para cada eletrodo através de um cálculo desenvolvido no grupo, que vem ajudando a obter bons resultados para as análises em café. Este cálculo fornece um valor da melhor freqüência, onde ocorre maior separação entre as substâncias com um menor desvio padrão. Sendo assim, as melhores freqüências obtidas para cada eletrodo estão apresentadas na tabela VII.

Tabela VII: Valores das melhores freqüências de trabalho para cada eletrodo.

\begin{tabular}{cc}
\hline Eletrodo & Freqüência $\mathbf{( K H z )}$ \\
\hline 1 & 70 \\
2 & 200 \\
3 & 200 \\
4 & 200 \\
5 & 300 \\
\hline
\end{tabular}

Após este cálculo, foi então verificado os valores de capacitância para cada eletrodo e cada substância, e com os valores obtidos foi feito a Análise de Componentes Principais (PCA).

A Figura 29 ilustra o gráfico de PCA obtido. Cada simbolo representa um dia de medida de cada substância. 


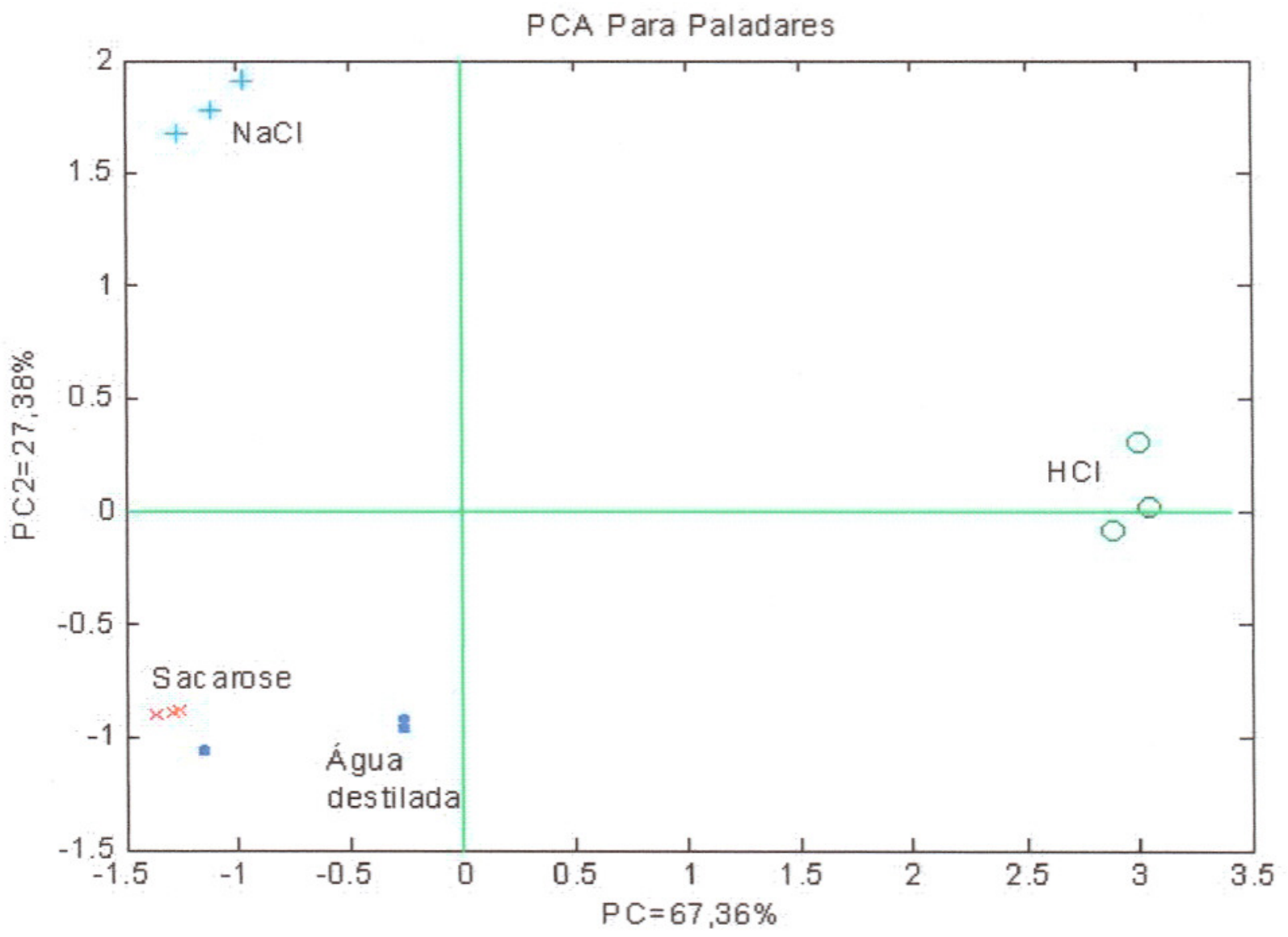

Figura 29- PCA para água destilada e paladares doce, azedo e salgado.

Como pode-se observar, o PCA obtido através dos valores de medidas de capacitância mostra que a Língua Eletrônica composta pelos filmes escolhidos apresentou uma boa discriminação dos paladares e a água destilada, indicando um potencial para a utilização desta língua eletrônica. Observa-se que para as substâncias que formam íons em solução como o $\mathrm{HCl}$ e $\circ \mathrm{NaCl}$, estes apresentam melhor separação, enquanto que para solução de sacarose e água destilada ocorre uma certa aproximação nos resultados. 
Foi realizado também, em parceria com a professora Danielle Dyminski da Universidade Federal do Paraná, medidas utilizando Edulcorantes. Esta parte do estudo teve como objetivo a avaliação de paladar utilizando a língua eletrônica em edulcorantes para comparação dos resultados obtidos com os resultados de degustadores, pois há grande interesse que a língua eletrônica possa ser uma ferramenta importante para o desenvolvimento de sabores similares a sacarose.

Os resultados apresentados aqui referem-se a capacidade de discriminação e classificação da língua eletrônica para a análise de edulcorantes. Foram analisadas onze soluções, sendo uma de sacarose como controle. A Tabela VIII apresenta os edulcorantes e suas combinações com suas respectivas concentrações e a concentração de sacarose utilizada para as medidas. Todas as soluções foram preparadas em água destilada. 
Tabela VIII- Edulcorantes, combinações de edulcorantes e sacarose com suas respectivas concentrações utilizadas para medidas com a Língua Eletrônica.

\begin{tabular}{cc}
\hline Substância & Concentração (g/100mL) \\
\hline Sacarose & 9,400 \\
Acesulfame-k & 0,080 \\
Aspartame & 0,063 \\
Ciclamato & 0,320 \\
Sacarina & 0,032 \\
Sucralose & 0,0143 \\
Sacarina + Ciclamato & 0,010 de Sacarina e 0,100 de Ciclamato \\
Acesulfame-k + Ciclamato & 0,0187 de Acesulfame-k e 0,0935 de Ciclamato \\
Acesulfame-k + Aspartame & 0,0215 de Acesulfame-k e 0,0215 de Aspartame \\
Sucralose + Ciclamato & 0,0077 de Sucralose e 0,1155 de Ciclamato \\
Sacarina + Ciclamato + Aspartame & 0,0067 de Sacarina, 0,067 de Ciclamato e 0,013 \\
& de Aspartame \\
\hline
\end{tabular}

Como explicado anteriormente, as concentrações e as proporções dos edulcorantes encontrados na Tabela VIII, são resultados de degustações realizadas por degustadores treinados, afim de se encontrar uma combinação e uma concentração que se assemelhe a doçura da sacarose.

Após a preparação das amostras foram realizadas medidas de capacitância com variação da freqüência $(1 \mathrm{~Hz}$ a $1 \mathrm{MHz})$ durante três dias consecutivos.

Utilizando-se o cálculo para a escolha da melhor freqüência para o estudo de PCA, chegou-se a um valor de $1 \mathrm{KHz}$ para todos os eletrodos. A Figura 30 ilustra o PCA obtido para as amostras de edulcorantes e sacarose. 


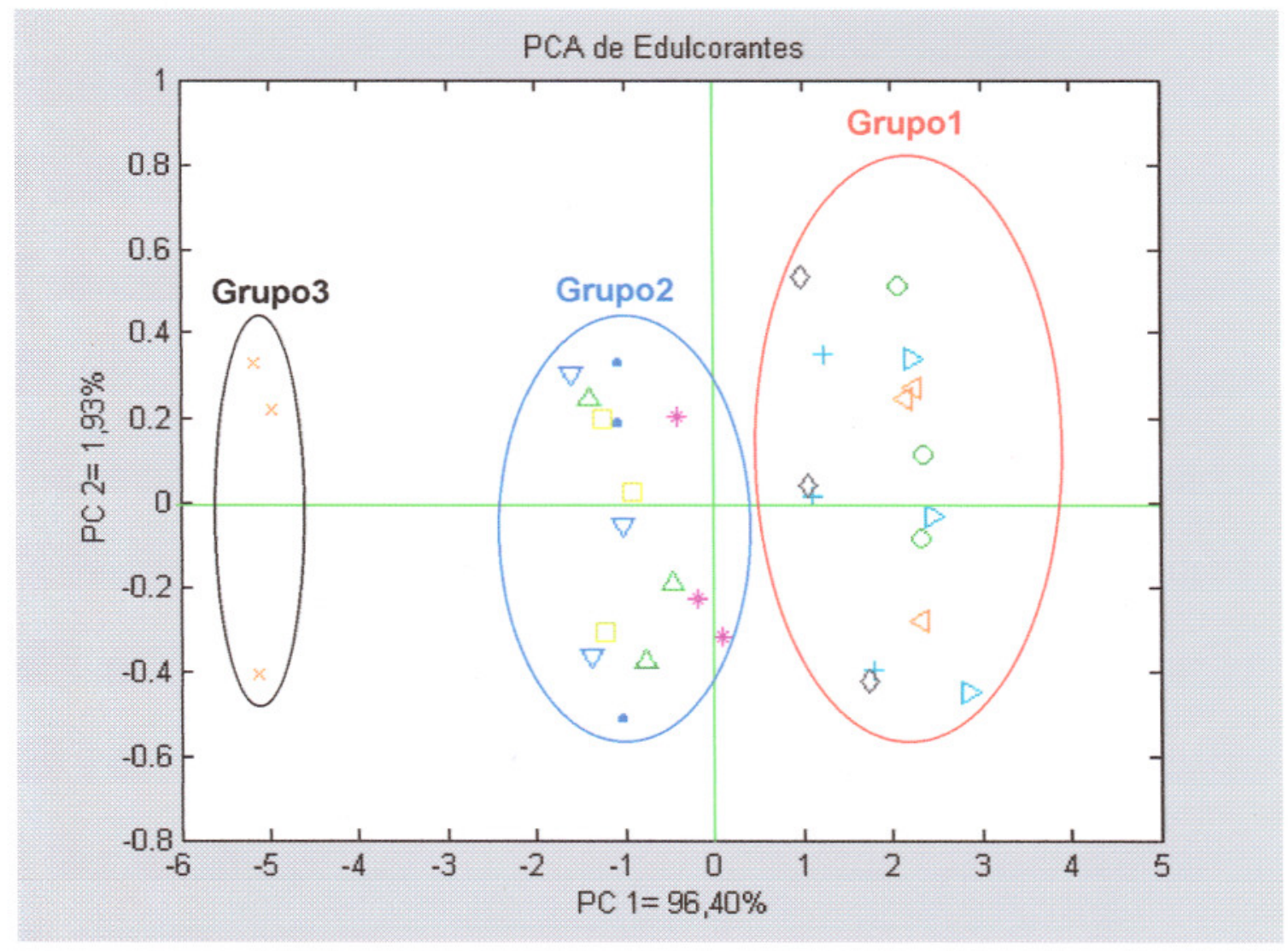

Fugura 30- PCA das soluções de edulcorantes e sacarose, realizadas em três dias consecutivos.

Legenda: $\triangleleft$ sacarose, $\triangleright$ sucralose, $\bigcirc$ Aspartame, +Sacarina, $\diamond$ Acessulfame+Aspartame, $\quad *$ Sacarina+ ciclamato + Aspartame, $\triangle$ Sacarina + ciclamato, $\nabla$ Ácessulfame + ciclamato, $\square$ sucralose + ciclamato, • Acessulfame, $x$ Ciclamato. 
Como pode-se observar $96,40 \%$ das informações são dadas em função de PC 1 e 1,93\% através de PC 2. Através deste PCA, pode-se separar informações em três grupos distintos, sendo o grupo 1, grupo 2 e grupo 3.

No Grupo 1 se encontra a maior semelhança dos edulcorantes com a sacarose. Estudos realizados por Thomson \& Tunaley [110] utilizando-se vários edulcorantes mostraram que, através de degustadores, o aspartame foi o edulcorante que apresentou as características mais próximas às da sacarose em doçura equivalente a uma solução de sacarose a $5 \%$. Homeler [111] também concluiu que o aspartame, em solução equivalente em doçura a uma solução de referência de sacarose a $10 \%$, apresenta gosto doce semelhante ao da sacarose. No grupo 1, ainda ocorre a presença de outros edulcorantes semelhantes a sacarose como a sucralose, sacarina e a solução de acessulfame misturado com aspartame.

No grupo 2, os edulcorantes sacarina + ciclamato + aspartame, sacarina + ciclamato + acessulfame, sucralose + ciclamato, acessulfame +ciclamato e acessulfame não apresentaram semelhança com a sacarose e o grupo 3 contendo somente ciclamato, é totalmente diferente de todos. Esta diferença pode ser explicada por a um sabor doce mais diferente dos outros edulcorantes, visto que esse edulcorante foi utilizado isoladamente. Observando-se o grupo 2 , nota-se que somente um adoçante não é combinado com o ciclamato, no caso ○ acessulfame. Uma explicação para este edulcorante estar presente neste grupo, é que este edulcorante pode apresentar um teor de doçura semelhante ao dos edulcorantes combinados. 
Sendo assim, as medidas de edulcorantes realizadas por esta Língua Eletrônica mostrou-se capaz de diferenciar e classificar edulcorantes ou combinações de edulcorantes que apresente semelhança em sabor ao da sacarose. 


\section{5-CONCLUSÕES}

Nesta dissertação os resultados obtidos pela técnica de automontagem, mostraram-se satisfatórios na obtenção de novos filmes ultra finos para serem utilizados para a preparação de unidades sensoriais da língua eletrônica. Para tanto, os estudos de UV-VIS foram de grande importância para a caracterização dos filmes e indicação de dopagem da solução polimérica.

Para filmes de POEA (em água) alternado com diferentes íons e políons, pôde-se observar a diferença entre a utilização de um eletrólito (DBSS) e um polieletrólito (PSS). Neste estudo verificou-se a formação de uma camada ultrafina de POEA e ao mesmo tempo sua dopagem. Neste caso o DBSS apresentou uma ligeira vantagem para adsorção e dopagem da POEA. Utilizando-se o ADBS, observou-se um maior poder de dopagem, mas uma adsorção menor de material, devido ao dopante provocar na cadeia polimérica da POEA uma repulsão intramolecular levando a uma conformação estendida, que faz com que ocorra uma repulsão de outras moléculas de polímero que se aproximam. Portanto, ao se utilizar uma solução de sal alternado com uma solução de POEA, conseguiu-se uma dopagem pelo deslocamento do equilíbrio de Donnan e quando utilizou-se um ácido a dopagem ocorreu por protonação.

Para a dopagem da solução de POEA com ADBS, foi necessário utilizarse a POEA-EB e um sistema solvente composto por $20 \%$ de DMAC e $80 \%$ de água mili-Q. Para esta dopagem utilizando-se o sistema solvente DMAC $+\mathrm{H}_{2} \mathrm{O}$, primeiramente deve-se adicionar o DMAC sobre o polímero, em seguida o dopante e por fim a água. Em outras ordens ocorria a precipitação da POEA. A utilização do novo sistema solvente DMAC e água proporcionou a formação de 
uma solução de POEA dopada com ADBS com maior estabilidade em comparação quando se usava somente a água.

Através dos estudos de microscopia de força atômica, estudou-se a diferença entre as morfologias dos filmes de POEA-ADBS (em DMAC e água) e POEA-ADBS (DMAC e água)/PSS (em água). Para estes filmes fabricados em pH 3,25 (POEA-ADBS e POEA-ADBS/PSS), verificou-se uma menor rugosidade para o filme de POEA-ADBS/PSS em relação ao filme contendo somente POEA-ADBS devido a formação de uma camada de PSS sobre a superfície de POEA-ADBS tornando-a menos rugosa, visto que a molécula de PSS não apresenta insaturações, logo possui grande flexibilidade

Para a fabricação do sensor, os filmes escolhidos apresentaram bons resultados durante as medidas elétricas dos testes de paladares, apresentando diferentes respostas para cada substância utilizada, formando uma impressão digital característica de cada solução analisada.

Para soluções que se ionizam, observou-se um alto valor de capacitância para cada sensor, e uma boa reprodutibilidade. Quando a substância medida foi a sacarose, esta por não apresentar a formação de ions quando em solução, apresentou baixos valores de capacitância. Através do gráfico de PCA verificouse uma boa capacidade da língua eletrônica para discriminar os paladares padrões. Analisando-se os edulcorantes, obteve-se um PCA que indicou boa capcidade da língua eletrônica para a discriminação dos edulcorantes e até mesmo edulcorantes que se assemelham em sabor com a sacarose. Assim os filmes aqui utilizados mostraram-se capazes de distinguir e classificar tipos diferentes de edulcorantes. 


\section{6- REFRÊNCIAS}

[1]- Toko, K.; Meas. Sci. Technol. 1998, 1919

[2]- Toko, K.; Electroanalysis 1998, 10, 657.

[3]- Toko, K.; Sens. Actuators B, 2000, 64, 205.

[4]- Di Natale, C.;Paolesse, R.; Macagnano, A.; David, F.; D'Amico, A.; Legin, A.; Vlasov, Y.; ; Rudnitskaya, A.; Selenev, B.; Sensor and Actuators B, 1997, 44, 423.

[5]- Legin, A.; Rudnitskaya, A.; Vlasov, Y.; Di Natale, C.; Mazzone E.; D’Amico, A.; Electroanalysis, 1999, 11, 814.

[6]- Legin, A.; Rudnitskaya, A.; Vlasov, Y.; Di Natale, C.; D’Amico, A.; Sensor and Actuators B, 1999, 58, 464.

[7]- Vlasov, Y.; Legin, A.; Rudnitskaya, A.; D’Amico, A.; Di Natale, C.; Sens. Actuators B, 2000, 65, 235.

[8]- Catálogo - Neotronics Scientific Ltd, Western House, 2 Cambridge Road, Stanted Mountfitchet, Essex CM24 8BZ (UK), 2001.

[9]- Skotheim, T.; Elsembauer, R.; Reynolds, J.R.; "Handbook of conducting polymers", ed. Marcel Dekker, NY (1998).

[10]- Souza, J.E.G.; Neto, B.B.; dos Santos, F.L.; de Melo, C.P.; Santos, M.S.; Ludermir, T.B.; Synthetic Metals 1999,102, 1296

[11]- Shurmer, H.V.; Corcoran, P.; Gardner, J.W.; Sensors and Actuators B, $1991,4,29$.

[12]- Stella, R.; Barisci, J.N.; Serra, G.; Wallace, G.G.; Rossi, D.D.; Sensors and Actuators B 2000, 63, 1 .

[13]- Hodgins, D.; Sensors and Actuators B 1995, 26/27, 255 
[14]- Selampinar, F.; Toppare, L.; Akbulut, U.; Yalçin, T.; Süzer, S.; Synthetic Metals 1995, 68, 109.

[15]- Riul, A. Jr.; Santos, D. S. Jr.; Wohnrath, K.; Di tommazo, R.; Carvalho, A. C. P. L. F., Fonseca, F. J.; Oliveira, O. N.; Taylor, D. M.; Mattoso, L. H. C.; Langmuir 2002, 18, 239.

[16]- Legin, A.; Rudnitskaya, A.; Vlasov, Y.; Di Natale, C.; Mazzone E.; D’Amico, A.; Sensor and Actuators B, 2000 65, 232.

[17]- Di Natale, C.;Paolesse, R.; Macagnano, A.; Mantini, A.; D'Amico, A.; Legin, .; Lavova, L.; Rudnitskaya, A.; Vlasov, Yu.; Sensor and Actuators B 2000, 64, 15.

[18]- Mattoso, L. H. C; Química Nova 1996, 19, 388.

[19]- Okabayashi, K.; Goto, F.; Abe, K.; Yoshida, t.; Synth. Met., 1987, 18, 365

[20]- Macdiarmid, A. G.; Epstein, A. J.; Proceedings of the First Conference on Frontiers of Polymer Research, India: 1991, Jan.

[21]- Genies, E. M.; Lapkowsk, M.; Santier, C.; Vieil, E.; Synth. Met., 1987, 18, 631.

[22]- Watanabe, A.; Mori, K.; Iwasaki, Y.; Nakmura, Y.; Niizuma, S.; Macromolecules, 1987, 20, 1793.

[23]- Macdiarmid, A. G.; Epstein, A. J.; The Polyanilines: Potential Teechonology Basead on New Chemistry and New Properties in Procceedings of teh European Physical Society Industrial Workshop Science and Application of Conducting Polymer Lofthus; Salaneck, W. R.; Clarck, D.T.; Eds.; IOP Publishing: Norway, 1990. 
[24]- Kogawa, M. et al.; $27^{\text {th }}$ Battery Symposium of Japan, Osaka, 1986, Enamoto, T.; Allen, D. P.; Bridgestone News Release, (Sept. 9, 1987); Chem. Week, 1987, 40, Oct.

[25]- Macdiarmid, A. G.; Yang, L. S.; Huang, W. S.; Humprey, B. D.; Synth. Met., $1987,18,393$.

[26]- Macdiarmid, A. G.; Materials at PENN 1992, 3, Mar.

[27]- Roth, S.; Grupner, W.; Synth Met., 1993, 55-57, 3623.

[28]- Neste Chemicals, Neste-Uniax new technology develepoment., Porvoo, finland, Catálago.

[29]- Uniax Corporation; UNIAX Polymer Conduct ${ }^{\mathrm{TM}}$, Santa Bárbara Catálago.

[30]- Gustafsson, G.; Cao, Y.; Treacy, G. M.; Klavetter, F.; Colaneri, N.; Heeger, A. J.; Nature, 1992, 357, 477.

[31]- Parker, I. D.; J. Applied Physics, 1994, 75, 1656.

[32]- Futuretech; Futuretech Strategic Markets 1992, n, 154.

[33]- Desphande, M. V.; Malnerkar, D. P.; Prog. Polymer Sci., 1993, 18, 623.

[34]- Schoch, K. F.; Saunders, H. E.; IEEE Spectrum 1992, 1, June.

[35]-Zoppi, R. A.; Depaoli, M. A.; Quimi. Nova, 1993, 16, 560.

[36]- Kaner, R. B.; Macdiarmid, A.G.; Scient. Am., 1988, 60, Feb.

[37]- Chiang, C. K..; Fincher, C. R.; Park, Y. W.; Heeger, A. J. ; Shirakawa, H..; Louis, E. J.; Grau, S. C.; Macdiarmid, A. G.; Phys.Rev. Lett, 1997, 39, 1098.

[38]-MacDiarmid, A. G.; Synth Met., 1997, 84, 27.

[39]- Miller, M. L.; Electral Properties In: The Structure of Poymers. Nova lorque: Reinhol Publishing Co., 1966, 657. 
[40]- Huang, W. S.; Humphrey, B. D.; MacDiarmid, A. G.; J. Chem. Soc. Faraday Trans. 1, 1986, 82, 2385

[41]- MacDiarmid A G.; Chiang, J. C.; Richter, A. F.; Epstein, A J.; Synth Met., 1987, 18, 285.

[42]- Netchtschein, M.; Genoud, F.; Nenardo, C.; Nizoguchi, K.; Travers, J. P.; Villeret, B.; Synth. Met., 1989, 29, E211.

[43]- Ray, A.; Asturias, G. E.; Kershner, D. L.; Richter, A. F.; Macdiarmid, A. G.; Epstein, A. J.; Synth. Met., 1989, 29, E141.

[44]- Macdiarmid, A. G.; Chiang, J. C.; Halpern, M.; Huang, W.S.; Um, S.L.; Somasiri, N. L. D.; Wu, W.; Yaniger, S. I., Mol. Cryst. Liq. Cryst., 1985, 121

[45]- Su, W. P.; Schrieffer, J. R.; Heeger, A. J.; Phys. Ver. B, 1980, 22, 2099.

[46]- Bredas, J. L.; Street, G. B.; Acc. Chem. Res. 1985, 18, 309.

[47]- Melo, C. P.; Ciência Hoje1987, 6, 38.

[48]-MacDiarmid, A. G.; Heeger, A. J.; Synth. Met. 1979/80, 1, 101.

[49]- Genies, E.M.; Boyle, A.; Lapkowski, M.; Tsintavis, C.; Synthetic Metals 1990, 36, 139.

[50]- MacDiarmid A G.; Chiang, J. C.; Richter, A. F.; Somasiri, N. L.. D.; Epstein, A J.; Conducting Polymers, In: Alcacer, L., Ed.; Reidel Pub, Dordrecht: Holland, 1987, 105.

[51]- Manohar, S. K.; MacDiarmid A G.; Epstein, A J.; Synth. Met. 1991, 41-43, 711. Sun, Y.; MacDiarmid A G.; Epstein, A J.; J. Chem. Soc., Chem. Commum. 1990, 529. MacDiarmid A G.; Epstein, A J.; The polyanilines: a 
[52]- Angelopoulos. M.; Asturias, G.E.; Erner, S. P.; Ray, A.; Scherr, E. M.; Macdiarmid, A. G.; Mol. Liq. Cryst. 1998, 160, 151.

novel class of conducting polymers, In: Conducting polymers, emerging technologies, Technical Insights Inc.: New Jersey, 1989, 27.

[53]- Angelopoulos, M.; Ray, A.; Macdiarmid, A. G.; Epstein, A. J.; Synth. Met.1987, 21, 21.

[54]- Manohar, S. K.; PhdThesis (University of Pensylvania), 1992.

[55]- Avlyanov, J.; Macdiarmid, A. G., in preparation.

[56]- Chan, H. S. O.; Ng, S, C.; Ho, P. K. H.; Macromolecules, 1994, 27, 2159.

[57]- Macdiarmid, A. G.; Manhohar, S. K.; Mattoso, L. H. C.; High molecular weights polyanilines and synthetic methods therefor, Patent Application, N: UPN-1157, USA, filed nov. 06, 1992.

[58]- MacDiarmid, A. G.; Synth. Met. 2002, 125, 11.

[59]- Kawagushi, M.; Takahashi. A.; Adv. In Coll. And Interf. Scien., 1992, 37, 220 .

[60]- Ulman, A.; An Introduction to Ultrathin Films: From Langmuir-Blodgett to Self Assembly, 1a Ed. Boston: Academic Press, 1991, 440.

[61]- Tópicos especiais em filmes finos orgânicos. Ad. Mater., 1991, 3, 3.

[62]- Langmuir, I.; J. Am. Chem. Soc.,1917, 39, 1848.

[63]- Blodget, K. B.; J. Am. Chem. Soc., 1935, 57,1007

[64]- Maoz, R.; Netzer, L; Gun, J.; Sagiv, J.; J. Chim. Phys. 1988, 83, 1509.

[65]- Paterno, L. G.; Mattoso, L. H. C.; Oliveira de, O. N. Jr.; Quimica Nova, $2001,24,2,228$

[66]- Decher, G.; Hong, J. D.; Macromol. Chem.Macromol Symp. 1991, 46, 321. 
[67]- Stockton, W. B.; Rubner, M. F.; Amer. Chem. Soc. 1997, 30, 2717. [68]Cheung, J. H.; Fou, A.; Ferreira, M.; Rubner, M. F.; Molecular selfassembly of conducting polymers: a new layer by layer thin film deposition process. Pol Preprints 1993, 34, 757.

[69]- Fou, A. C.; Ellis, D.; Ferreira, M.; Rubner, M. F.; Layer-by-layer molecular self-assembly of conducting polymer heterostructure. Pol. Preprints, 1994, 35, 221.

[70]- Paterno, L. G; Mattoso, L. H. C.; Journ. Of Appl. Pol. Sci. 2001, 83, 1309.

[71]- Mattoso, L. H. C; Paterno, L. G.; Campana, S. P.; Oliveira Jr., O. N.; Synthetic Metals 1997, 84, 123.

[72]- Mattoso, L. H. C; Zucolotto, V.; Paterno, L. G.; van Griethuijsen, R.; Ferreira, M.; Campana, S. P.; Oliveira Jr., O. N.; Synthetic Metals 1995, $71,2037$.

[73]- Paterno, L. G.; Constantino, C. J. L.; Oliveira Jr., O. N.; Mattoso, L. H. C.; Colloids and Surfaces 2002, 23, 257.

[74]- Ferreira, M.; Cheung, J. H.; Rubner, M. F.; Molecular self-assembly of conjugated polyions: a new process of fabrication multilayer thin film hetrostructure. Thin Solid Films 1994, 244, 806.

[75]- Ivarsson, P.; Holmin, S.; Hojer, N.E.; Rulcker, C. K.; Winquist, F.; Sens. and Actuat. B, 2001, 76, 449

[76]- Winquist, F.; Holmin, S.; Rulcker, C. K.; Wide, P.; Lundström, I.; Anal. Chem. Acta, 2000, 406, 147

[77]- Toko, K.; Biosens. and Bioelect., 1998, 13, 701. 
[78]- Riul Jr., A.; Malmegrim, R. R.; Fonseca, F. J.; Mattoso, L. H. C. Biosensors and Bioelectronics 18, 11 (2003) 1365-1369.

[79]- Das Neves, S. Propriedades Fotoeletroquímicas da Polianilina. Campinas. Tese (Doutorado) Instituto de Química da Universidade Estadual de Campinas, 1997.

[80]- Fatibello Filho, O.; da Cruz Vieira, I.; Gouveia, S. T.; Calafatti, S. A.; Química Nova, 1996, 19, 3, 248.

[81]- Corey, E. J.; Seebach, D.; Angnew. Chem. internat. Edit., 1965, 1075, 1077.

[82]- Weast, R. C.; Handbook of Food Additives; Furia, T. E., Ed.; The Chemical Rubber Co.; 1986; 501.

[83]- Splenda ${ }^{\circledR}$ - Sucralose.

[84]- Cândido, L. M. B.; Campos, A. M.; Alimentos para fins especiais: DIETÉTICOS, Livraria Varella, São Paulo 1996.

[85]- Mattoso, L. H. C; Manohar, S. K.; MacDirmid, A. G.; Epstein, A. J.; J. Polymer Sci.: Part A: Polym. Chem. 1995, 33, 1227.

[86]- Dhawan, S. K.; Trived, D. C.; Synth. Met., 1993, 60, 67.

[87]- Kern, W.; Semi Cond. Int. 1984, 94.

[88]- Leonardi, M. Acesulfame-k. In: Edulcorantes e Adoçantes em Alimentos. (1990: Campinas). Edulcorantes e Adoçantes em Alimentos : Ciclo de Debates. Campinas: ITAL, 1990 a, p. 10-15. 
[89]-Wells, A . G. The use of intense sweeteners in soft drinks. In: Grenby, T. H. Progress in sweeteners. London: Elsevier Applied Science, 1989. 169 214.

[90]- Cândido, L. M.; Bileski; C.; Mulinari, A.; Alimentos para Fins Especiais: Dietéticos. São Paulo: Varela, 1996.

[91]- Gava, A. J. Os diabéticos e as bebidas de baixa caloria e o açúcar: o que fazer? Ponto de vista do fabricante de refrigerantes. Alimentação, São Paulo, n. 83, p. 10 - 14, maio/ago. 1986.

[92]- Montijano, H.; Tomas-Barberán, A.; Borrego, F.; Propiedades tecnológicas y regulación de los edulcorantes de alta intensidad en la Unión Europea. Food Science and Technology International, v. 4, n. 1, p. 5-16, 1998.

[93]- SUNETT - Sweet - Stable - Safe. Frankfurt: Hoescht, Aug. 1992. Publicação Técnica.

[94]- Lipinsk; Debney, T. J.; Properties and applications of acesulfame-k. Food Australia, v. 45, n. 12, p. 588-592, Dec. 1993.

[95]- SUNETT - The Sunett multi - sweetener concept. Frankfurt : Hoechst. Aug. 1991. Publicação Técnica.

[96]- Decher, G.; Hong, J. D.; Ber. Bunsenges. Phys. Chem. 1991, 95, 11, 1430.

[97]- Binning, G.; Quate, C. F.; Gerber, C; Phis. Ver. Lett 1986, 56, 9, 930.

[98]- Stockton, W. B.; Rubner, M. F.; Macromolecules 1997, 30, 2717.

[99]- Zheng, W.; Angelopolulos, M.; Epstein, A. J.; MacDiarmid, A. G.; Macromolecules 1997, 30, 2953.

[100]- Raposo, M. F. G. S. C; Tese de Doutorado em Ciências e Engenharia de Materiais - Instituto de Física de São Carlos, Instituto de Química de São 
Carlos, Escola de Engenharia de São Carlos, Universidade de São Paulo 1999, 209.

[101]- Paterno, L. G.; Mattoso, L. H. C.; Polymer 2001, 42, 5239.

[102]- MacDirmid, A. G.; Epstein, A. J.; Mat. Res. Soc. Symp. Proc., 1992, 247, 565.

[103]- Raposo, M.; Oliveira Jr.; O. N.; Langmuir 2002, 18, 6866

[104]- Kawagushi, M.; Takahashi, A.; Adv. Coll. Inter. Sci. 1992, 37, 219.

[105]- Lvov, Y.; Decher, G.; Mohwald, H.; Langmuir 1993, 9, 481.

[106]- Rosen, M. J.; Surfactants and Interfacial Phenomena $2^{\circ}$ ed., John Wiley \& Sons, 1988, 33 .

[107]- Pontes, R. S.; Raposo, M.; Camilo, C. S.; et. al.; Phys. Stat. Sol. A-Appl. Res., 1999, 173, 1, 41.

[108]- Cao, Y.; Smith, P.; Heeger. A. J.; Synth. Met. 1993, 55-57, 3514.

[109]- Jana, T.; Nandi, A. K.; Langmuir 2000, 16, 3141

[110]- Thomson \& Tunaley in: Cordello, H. M. A. B.; Da Silva, M. A. P.; Damásio, M. H.; Avanços em Análise Sensorial, Editora Varela, 1999, 213.

[111]- Homeler in: Cordello, H. M. A. B.; Da Silva, M. A. P.; Damásio, M. H.; Avanços em Análise Sensorial, Editora Varela, 1999, 213. 